\title{
Differences in Smoking Behaviors and Readiness to Change for Patients with COPD and Differing Categories of Depression
}

\author{
Jessica M. Floyd \\ West Virginia University, jmf0002@mix.wvu.edu
}

Follow this and additional works at: https://researchrepository.wvu.edu/etd

Part of the Geriatric Nursing Commons, Mental Disorders Commons, Psychiatric and Mental Health Commons, and the Public Health and Community Nursing Commons

\section{Recommended Citation}

Floyd, Jessica M., "Differences in Smoking Behaviors and Readiness to Change for Patients with COPD and Differing Categories of Depression" (2021). Graduate Theses, Dissertations, and Problem Reports. 8268.

https://researchrepository.wvu.edu/etd/8268

This Dissertation is protected by copyright and/or related rights. It has been brought to you by the The Research Repository @ WVU with permission from the rights-holder(s). You are free to use this Dissertation in any way that is permitted by the copyright and related rights legislation that applies to your use. For other uses you must obtain permission from the rights-holder(s) directly, unless additional rights are indicated by a Creative Commons license in the record and/ or on the work itself. This Dissertation has been accepted for inclusion in WVU Graduate Theses, Dissertations, and Problem Reports collection by an authorized administrator of The Research Repository @ WVU.

For more information, please contact researchrepository@mail.wvu.edu. 
Differences in Smoking Behaviors and Readiness to Change for Patients with COPD and Differing Categories of Depression Jessica M. Floyd 
Differences in Smoking Behaviors and Readiness to Change for Patients with COPD and Differing Categories of Depression

\title{
Jessica Floyd
}

\author{
Dissertation submitted \\ to the School of Nursing \\ at West Virginia University
}
in partial fulfillment of the requirements for the degree of
Doctor of Philosophy in
Nursing

\author{
Jennifer Mallow, Ph.D., FNP-BC, Chair \\ Laurie Theeke, Ph.D., FNP-BC, GCNS-BC, FAAN \\ Roger Carpenter, Ph.D., RN, NE-BC, CNE \\ Kesheng Wang, Ph.D. \\ Steve Davis, Ph.D. \\ School of Nursing
}
Morgantown, West Virginia
2021

Keywords: Chronic obstructive pulmonary disease, COPD, depression, smoking

Copyright 2021 Jessica Floyd 


\begin{abstract}
Differences in Smoking Behaviors and Readiness to Change for Patients with COPD and

Differing Categories of Depression
\end{abstract}

Jessica Floyd

Background: Chronic obstructive pulmonary disease (COPD) is the third leading cause of death in the world. Depression is a common comorbidity of COPD and affects patient outcomes and smoking cessation. The purpose of this study was to explore and describe factors influencing smoking behaviors and readiness to change in patients with comorbid COPD and depression. Aims: The research question that guided this study was, "What are the relationships among smoking, COPD, and depression?" The following aims stemmed from the research question: to describe the characteristics of a convenience sample of people living with COPD and differing categories of depression who sought care in West Virginia; to describe the differences between people with COPD and differing categories of depression (minimal, mild, moderate, moderately severe, severe, or no depression) related to smoking behaviors and readiness to change; to explore the relationships among COPD, depression, smoking behaviors, and readiness to change; and to analyze the relationships among COPD, depression, smoking behaviors, and readiness to change.

Methods: A descriptive cross-sectional design was used. A convenience sample of 222 COPD patients participated in the study. COPD was self-reported. Depression was assessed through the PHQ-9. Smoking behaviors were assessed through The Cigarette Dependence Scale. Readiness to change was assessed through The Smoking Stage of Change Questionnaire, The Smoking Decisional Balance Questionnaire, and The Processes of Change Questionnaire. Electronic and paper questionnaires were collected using various recruitment strategies. Data was stored in RedCap and analyzed using SPSS version 26. Descriptive analyses were conducted and ANOVA, t-test, chi-square, Pearson correlation, linear regression, and multiple linear regression were used to analyze the relationships among smoking, COPD, and depression.

Results: Most participants were older white females who were of lower socioeconomic status that completed high school or some college. Diabetes mellitus and congestive heart failure were the most prevalent comorbid conditions. Only 18 participants were classified as having no depression. The majority of participants were in the maintenance or contemplation stage. Participants who smoked had high nicotine dependence and wanted to quit smoking. Overall, participants saw more cons to smoking and were engaged in the processes of change.

Conclusions: There is a need to assess COPD patients for depression and to assess COPD patients' smoking behaviors and readiness to change. Depression does affect patients' smoking behaviors and readiness to change. Adequate treatment of depression could promote an individual to move through the stages of change from chronic contemplation to action, thus improving smoking cessation efforts for individuals with COPD. Understanding patients' smoking behaviors and readiness to change can aid in developing personalized interventions to achieve smoking cessation and long-term outcomes. 


\section{Table of Contents}

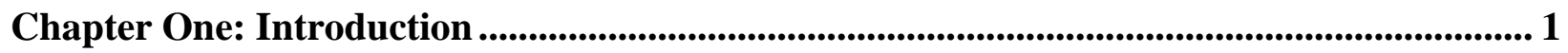

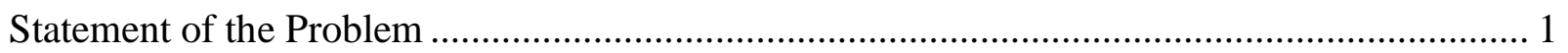

Background of the Problem............................................................................................. 2

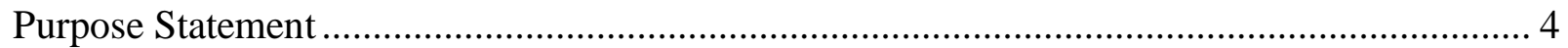

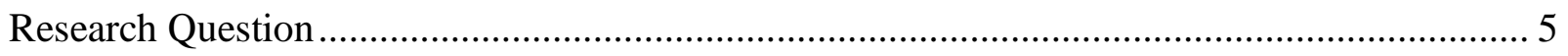

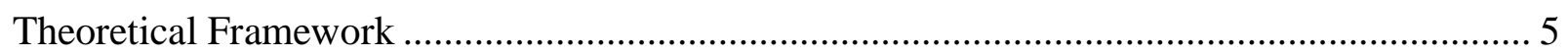

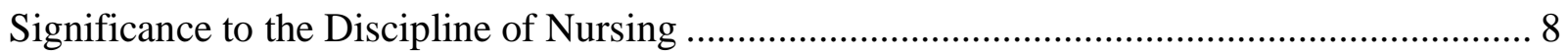

Chapter Two: Review of the Literature...................................................................................... 11

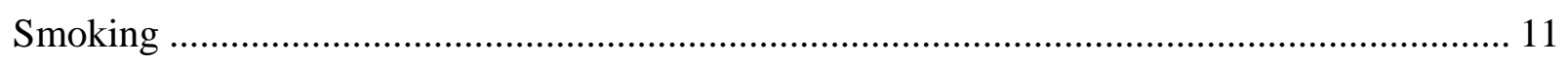

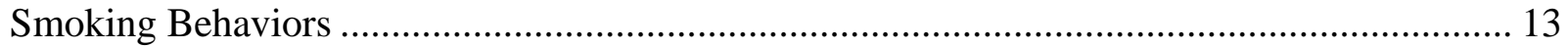

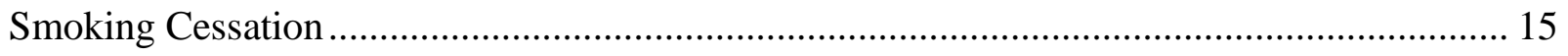

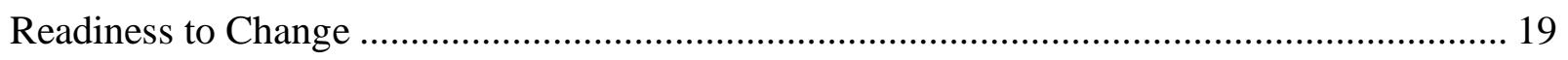

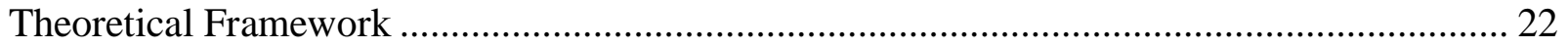

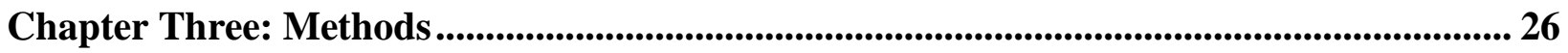

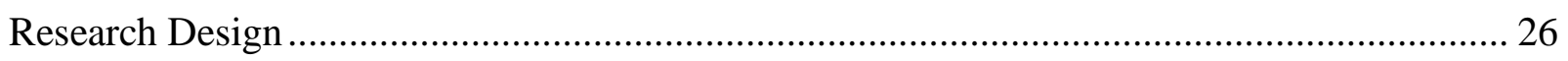

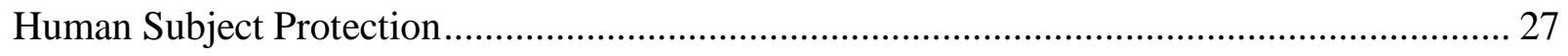

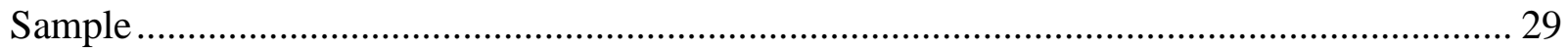

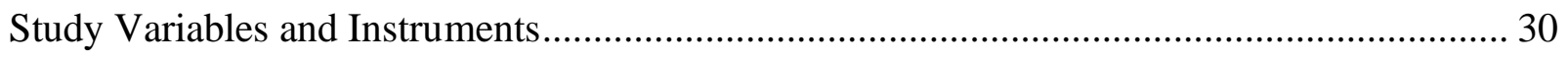

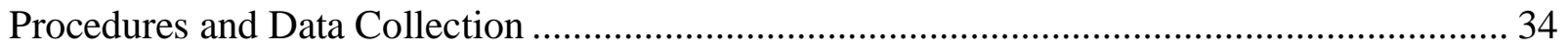

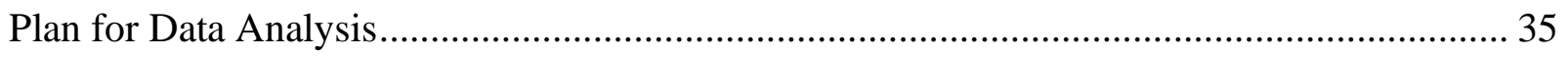

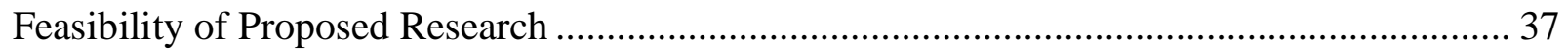

Chapter Four: Results ............................................................................................................................... 39

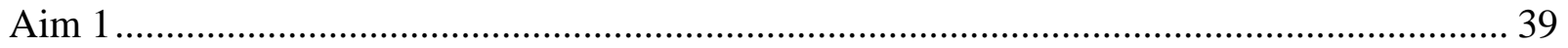

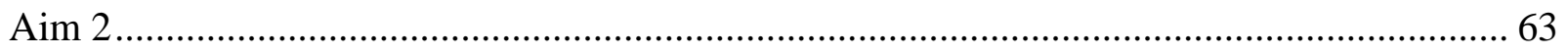

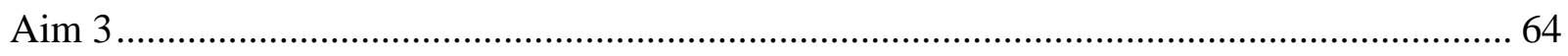

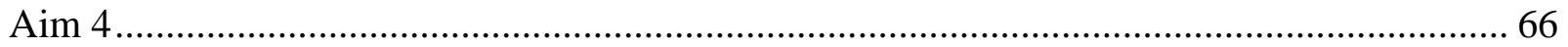

Chapter Five: Findings.............................................................................................................................. 70

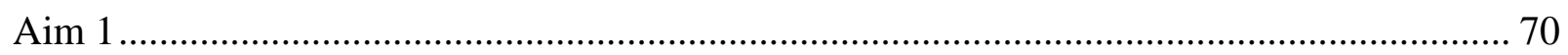




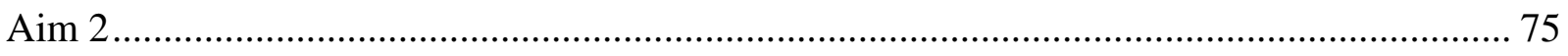

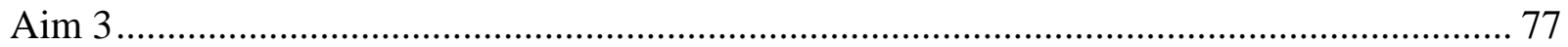

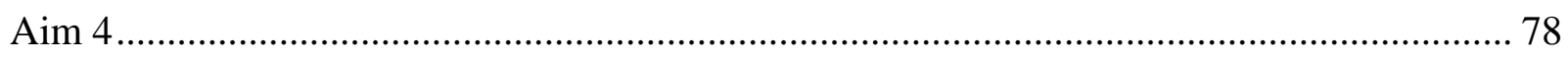

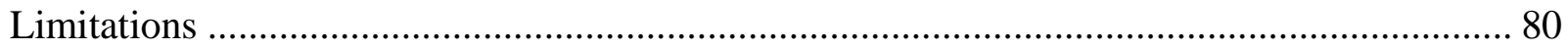

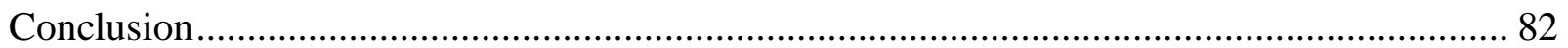

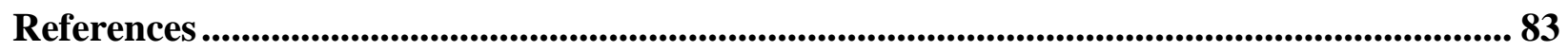




\section{Chapter One: Introduction}

Tobacco is a worldwide epidemic. Although differing forms of tobacco exist, $90 \%$ of tobacco used is through cigarette smoking (Prochaska, Das, \& Young-Wolff, 2017). Smoking is the leading source of death and preventable diseases (Centers for Disease Control and Prevention, 2019a). Globally, 7 million people die each year from tobacco (World Health Organization, 2019). In the United States, the burden of tobacco is vast. Approximately 34 million adults in America smoke, and tobacco causes one out of every five deaths in the country (Centers for Disease Control and Prevention, 2019a). Treatment for smoking-related diseases costs the United States approximately $\$ 170$ billion in medical expenses annually (Centers for Disease Control and Prevention, 2019b). This chapter introduces the difficulty of achieving smoking cessation, the physical and psychological consequences of smoking, and how individuals' smoking behaviors and their readiness to change influences smoking cessation.

\section{Statement of the Problem}

Smoking cessation is difficult, and nicotine withdrawal impacts physical and psychological health. The difficulty of quitting nicotine addiction is comparable to heroin (Smoke Free, 2019a). Nicotine, the addictive component in cigarettes, controls the brain. While smoking, the brain receives regular doses of nicotine, and over time, the brain develops extra nicotine receptors (Smoke Free, 2019a). When the brain receives reduced levels of nicotine, an individual begins to experience nicotine withdrawal (Smoke Free, 2019a). Nicotine withdrawal can cause difficulty sleeping and an increased appetite (Smoke Free, 2019b). It can also cause cravings, irritability, sadness, and poor concentration (Smoke Free, 2019b). Although experiencing these symptoms can be difficult, continuing to smoke has a significant negative consequence on an individual's physical and psychological health (Smoke Free, 2019a). 


\section{Background of the Problem}

\section{Physical Impact of Smoking}

Smoking negatively affects almost every organ in the human body (Centers for Disease Control and Prevention, 2018). Currently, 16 million Americans suffer from smoking-related diseases (Centers for Disease Control and Prevention, 2019a). Smoking leads to many different types of cancers, including, lung, esophageal, liver, pancreatic, and stomach (Centers for Disease Control and Prevention, 2018). By increasing the blood viscosity and causing vasoconstriction of the blood vessels, smoking causes hypertension and thrombus formation. This formation leads to cardiovascular diseases, such as coronary heart disease and cerebral vascular accidents. By damaging the alveoli in the lungs, smoking also leads to or worsens lung diseases, such as chronic obstructive pulmonary disease (COPD), asthma, chronic bronchitis, and emphysema (Centers for Disease Control and Prevention, 2018). In the United States, 11 million people have COPD, and millions more may be undiagnosed (American Lung Association, 2017). Despite the physical consequences of smoking, it is often the psychological impact of smoking that makes it difficult to achieve cessation.

\section{Psychological Impact of Smoking}

Nicotine causes physiological changes in the brain (Mental Health Foundation, 2019). The prevalence of smoking is highest in individuals diagnosed with bipolar disorder, substance use disorders, schizophrenia, depression, and post-traumatic stress disorders. In the schizophrenic population, smoking is known to cause poor problem-solving skills and poor verbal memory. In the bipolar population, smoking is associated with more severe and frequent psychiatric symptoms (El-Mallakh, McPeak, Khara, \& Okoli, 2016). In the United States, approximately 17.3 million adults report having a depressive episode (National Institute of 
Mental Health, 2019). Being a smoker doubles an individual's risk for developing depression, and in heavy smokers, that risk quadruples (Prochaska et al., 2017).

\section{Smoking Cessation}

More than half of adult smokers desire to achieve smoking cessation; however, physiological and psychological factors exist that make this process very challenging (Centers for Disease Control and Prevention, 2017). Smoking was once viewed as a bad habit, but it is now seen as tobacco use disorder, a chronic and relapsing disease (Woody, DeCristofaro, \& Carlton, 2008). Changing this health behavior is a complex process, and the majority of smokers are not ready to implement change (Prochaska \& Velicer, 1997). If an individual is not ready to implement change, most cessation attempts will fail, and relapse will occur. Individuals’ readiness to change should be assessed prior to implementing smoking cessation interventions for optimal outcomes (Woody et al., 2008).

\section{Smoking Cessation and Psychological and Behavioral Health}

In addition to being ready to change, individuals with a psychological and behavioral health diagnosis have additional challenges when trying to achieve smoking cessation. In the United States, these individuals consume nearly half of the cigarettes sold (Prochaska et al., 2017). They have greater nicotine dependence, resulting in increased withdrawal symptoms and fewer quit attempts. On average, smokers with psychological and behavioral health diagnoses die 25 years earlier (Prochaska et al., 2017). With the consistent prevalence of smoking in this population, it is apparent that smoking cessation interventions for the general population are not effective for individuals with a psychological and behavioral health diagnosis (Prochaska et al., 2017). 


\section{Smoking in West Virginia}

The impact of smoking on COPD and depression is evident in West Virginia. In 2017, West Virginia led the United States with the highest percentage of smoking adults at $26 \%$ (United Health Foundation, 2019). In 2015, West Virginia had the highest prevalence of COPD in the United States at 12.1\% (American Lung Association, 2017). The prevalence of depression among Medicare patients in West Virginia is $16.7 \%$, which differs from the United States as a whole, in which the prevalence of depression among Medicare patients is $15.4 \%$ (Appalachian Regional Commission, 2017). There is a need to explore how depression as a comorbidity affects smoking behaviors and readiness to change in the COPD population of West Virginia.

\section{Relevance of the Problem}

The 2025 Healthy People goal is to reduce tobacco use in the United States to $12 \%$ (Prochaska et al., 2017). To improve smoking cessation outcomes, interventions are needed to address smoking behaviors concurrently with psychological and behavioral health symptoms (ElMallakh et al., 2016). Given the prevalence of COPD and depression for the state of West Virginia, there is a critical need to understand factors impacting cessation in this population. Smoking cessation can alter the physical and psychological effects of smoking; however, individuals need to be ready to implement change.

\section{Purpose Statement}

The purpose of this study was to explore and describe factors influencing smoking behaviors and readiness to change in patients with comorbid COPD and depression. Factors that influence smoking behaviors and readiness to change may contribute as facilitators and/or barriers to achieving smoking cessation. 


\section{Research Question}

The research question guiding this study was, "What are the relationships among smoking, COPD, and depression?" The following aims stemmed from the research question: to describe the characteristics of a convenience sample of people living with COPD and differing categories of depression who sought care in West Virginia; to describe the differences between people with COPD and differing categories of depression (minimal, mild, moderate, moderately severe, severe, or no depression) related to smoking behaviors and readiness to change; to explore the relationships among COPD, depression, smoking behaviors, and readiness to change; and to analyze the relationships among COPD, depression, smoking behaviors, and readiness to change.

\section{Theoretical Framework}

The Transtheoretical Model was the theoretical framework that guided this study. The Transtheoretical Model calls for a paradigm shift and assumes that changing a health behavior takes time and requires progression through a series of stages. This comprehensive model integrates multiple theories on the belief that a single theory cannot explain the intricacies of behavior change. It challenges the belief that action-oriented programs are for everyone - also known as the action paradigm — and calls for a stage paradigm. A stage paradigm assumes that the majority of individuals are not ready to take action. Instead, the Transtheoretical Model assesses the essence of the behavior, identifies the stage of change individuals are in, and then selects stage specific interventions that aid in promoting change. This approach is designed to personalize interventions and enhance personal self-control. The Transtheoretical Model includes five stages of change, ten processes of change, decisional balance, self-efficacy, and temptation (Prochaska \& Velicer, 1997). 


\section{Five Stages of Change}

The core constructs of the Transtheoretical Model include the following five stages of change: precontemplation, contemplation, preparation, action, and maintenance.

Precontemplation refers to individuals who are not ready to change. These individuals do not recognize the consequences of their health behaviors and have no intention of acting within the next six months. Contemplation refers to individuals who are planning to change within the next six months. Individuals in this stage contemplate the positive and negative aspects of changing their health behavior. Often times, uncertainty causes individuals to dwell in the contemplation stage. This is referred to as chronic contemplation or behavioral procrastination. Preparation refers to individuals who have a plan to act within the next month. Action refers to individuals who have altered their behavior within the past six months. Maintenance refers to individuals who are continuing with their change behavior and are trying not to regress to a previous stage. The maintenance stage can last from six months to five years (Prochaska \& Velicer, 1997).

\section{Ten Processes of Change}

To progress from one stage to another, individuals use the following ten processes of change: consciousness raising, dramatic relief, self-reevaluation, environmental reevaluation, self-liberation, social liberation, counterconditioning, stimulus control, contingency/ reinforcement management, and helping relationships (Prochaska \& Velicer, 1997). Consciousness raising refers to when individuals recognize the health behavior and acknowledge the consequences. Dramatic relief refers to when individuals have experiences that produce heightened emotions. Grieving, listening to a testimony, or role playing are all examples of dramatic relief. Self-reevaluation refers to when individuals reevaluate their self-image in the presence of and without the health behavior. Environmental reevaluation refers to when 
individuals assess how their health behavior affects their social environment. Self-liberation refers to when individuals believe they can change and can also commit and recommit to change. Social liberation refers to when individuals experience more social opportunities.

Counterconditiong refers to when individuals learn that a new health behavior can replace a poor health behavior. Stimulus control refers to when individuals remove unhealthy behavior cues and replace them with prompts for healthy behavior. Contingency/reinforcement management refers to when individuals face consequences or receive rewards for certain decisions. Helping relationships refer to when individuals experience social support for their new health behavior (Prochaska \& Velicer, 1997).

\section{Decisional Balance, Self-Efficacy, and Temptation}

The Transtheoretical Model also includes the constructs of decisional balance, selfefficacy, and temptation. Decisional balance refers to the pros and cons individuals consider when they are making a change. Self-efficacy refers to individuals' confidence related to their changed behavior and their will not to regress to previous stages. Temptation refers to the urges individuals experience when they are placed in challenging situations (Prochaska \& Velicer, 1997). For this study, decisional balance was measured. Self-efficacy and temptation were not measured in this research study.

The Transtheoretical Model provided a framework for exploring factors influencing smoking behaviors and readiness to change for individuals with comorbid COPD and depression (Prochaska \& Velicer, 1997). This model provided a lens to understand how depression as a comorbidity impacts smoking behavior and readiness to change for patients with COPD. The core constructs of the Transtheoretical Model guided inquiry on this research problem and provided a framework for focusing on caring in the human health experience. 


\section{Significance to the Discipline of Nursing}

This study on smoking behaviors and readiness to change contributes to the body of nursing knowledge. The perspective of the discipline of nursing is caring in the human health experience (Newman, Sime, \& Corcoran-Perry, 1991). To stimulate inquiry for the discipline, caring in the human health experience provides a philosophical lens for knowledge development. New knowledge must address caring and human health experience to be considered nursing knowledge (Newman et al., 1991). Smoking behaviors, readiness to change, stages of change, and processes of change are all integral parts of the human health experience. To generate new nursing knowledge, one must care for individuals, understand their human health experience, and examine how depression as a comorbidity impacts their experience. This study was grounded in the philosophical perspective of caring in the human health experience to ensure sound knowledge was developed (Polifroni \& Welch, 1999).

\section{Implications for Nursing Practice}

Newly generated knowledge about the human health experience of smoking behaviors and readiness to change also is expected to be foundational in developing new implications for nursing practice. Individuals with COPD and depression are a vulnerable population, and it is imperative that their complex health care needs are addressed. Findings from this study will help identify factors that may aid in the management of individuals with COPD and depression. This study is innovative in its approach, because people with comorbid COPD and depression who sought care in West Virginia, are an understudied population of disparity.

\section{Implications for Health Policy}

It is expected that the findings from this study will have policy implications related to adequate smoking cessation tools in West Virginia. The Centers for Disease Control and 
Prevention (CDC) recommends that West Virginia allocate \$27.4 million for tobacco prevention. However, for the 2017 fiscal year, the state allocated \$3 million, and for the 2018 fiscal year, the state did not fund tobacco prevention (American Cancer Society Cancer Action Network, 2017). Established in 2000, the West Virginia Tobacco Quitline is a free service available to West Virginia residents to aid in tobacco cessation. The Quitline provides free educational materials, four free phone calls from Quitline coaches, and eight weeks of free nicotine replacement therapy. The Quitline coaches are trained in motivational interviewing and behavioral modification (Division of Tobacco Prevention, 2018). Currently, the Quitline is the busiest Quitline per capita in the United States with more than 70,000 participants enrolled since 2000; however, the Quitline has a quit rate of only 33.4\% (Division of Tobacco Prevention, 2018). It is possible that a policy change designed to target interventions for individuals with comorbid COPD and depression would result in increased quit rates. The findings from this study are aimed to identify how individuals with COPD and depression progress through the stages of change, and this would provide new targets for smoking cessation treatment. Finally, results from this study provide understanding of the population's smoking cessation behaviors, and this information could provide justification for future funding.

\section{Conclusion}

Smoking is the world's greatest public health threat (Organization, 2019). To reach the 2025 Healthy People goal and reduce tobacco use in the United States to $12 \%$, studies are needed that include people who are current tobacco users and diagnosed with comorbid COPD and depression (Prochaska et al., 2017). Exploring factors that influence smoking behaviors and readiness to change in this population will contribute knowledge that can aid in reaching this 
goal. An integrated literature review is presented in Chapter 2. The variables that are considered in the literature are COPD, depression, smoking behaviors, and readiness to change. 


\section{Chapter Two: Review of the Literature}

The purpose of this study was to explore and describe factors influencing smoking behaviors and readiness to change in patients with comorbid COPD and depression. A broad integrated literature review was conducted on the variables: COPD, depression, smoking behaviors, and readiness to change. The findings from the literature are synthesized in this chapter.

\section{Smoking}

The tobacco epidemic poses physical and psychological health consequences around the world. Nicotine, a natural pesticide on tobacco leaves, is the leading addictive property in cigarettes (Prochaska et al., 2017). This addictive property causes the majority of cigarette smokers to develop nicotine dependence (Goodwin et al., 2012). Dependence on nicotine is considered a mental disorder, according to the Diagnostic and Statistical Manual of Mental Disorders (DSM-IV) (Goodwin et al., 2012).

\section{Physical Impact of Smoking}

Smoking increases individuals' vulnerability to medical illnesses (El-Mallakh et al., 2016). It is a modifiable risk factor for many diseases, such as cancer, cardiovascular diseases, and respiratory diseases, and it negatively affects overall health (Centers for Disease Control and Prevention, 2018). In a study looking at the relationship between smoking and physical and psychological health, findings showed that smokers report worse physical health than nonsmokers. Physical health was measured by physical function, role function, body pain, and general health. Using the Short Form Health Survey (SF-36), a higher score indicated a better physical health status. For smokers, the scores in the four physical health categories were 1113\% lower than nonsmokers (Woolf et al., 1999). Smoking can also exacerbate other conditions. 
In individuals with impaired mobility, smoking can cause a decrease in strength and endurance (Lee, Park, Kim, \& Shin, 2014). The effects of smoking can also go unnoticed. It is estimated that $31-45 \%$ of "healthy" smokers do, in fact, have COPD (Toljamo, Kaukonen, Nieminen, \& Kinnula, 2010).

\section{Psychological Impact of Smoking}

An association exists between smoking behaviors and a psychological and behavioral health diagnosis (Shi, 2014). Smoking is most prevalent in patients with a psychological and behavioral health diagnosis. Tobacco use is also reported as a risk factor for developing a psychological and behavioral health diagnosis (Michal et al., 2013). There is a dose-response relationship between smoking behaviors and anxiety and mood disorders (Goodwin et al., 2012). Smoking has also been identified as a predictor of suicide attempts and other substance use (Prochaska et al., 2017). Furthermore, smoking behavior impacts disease management and outcomes. Nicotine can interact with the therapeutic levels of certain psychiatric medications (Prochaska et al., 2017) and has been identified as a contributing factor to diminishing promotion activities in those with a psychological and behavioral diagnosis (El-Mallakh et al., 2016). In the United States, more than $40 \%$ of tobacco-related deaths reported are individuals with a psychological and behavioral health diagnosis (King, Reboussin, Spangler, Cornacchione Ross, \& Sutfin, 2018).

\section{Biobehavioral Impact of Smoking}

A relationship exists between the physical and psychological consequences of smoking. This relationship is bidirectional, in which each component can influence the other. Compared to those who are physically ill, patients who suffer from depression and a chronic illness are less likely to be social and physically active (Yohannes, Hann, \& Sibbald, 2011). These patients are 
also more likely to be non-adherent with medical care. These health behaviors affect health outcomes and lead to premature deaths (Yohannes et al., 2011). Higher depression levels also correlate with physical symptoms, such as shortness of breath, fatigue, and frequency of COPD symptoms (Bratek et al., 2015). Likewise, with an increased severity of COPD, an increased prevalence of depression is seen in those who smoke (Bratek et al., 2015).

\section{Smoking Behaviors}

Smoking is a behavior that is characterized by the differing actions associated with smoking cigarettes. Common measurable smoking behaviors include smoking status, frequency of use, and nicotine dependence levels.

\section{Smoking Behaviors and Psychological and Behavioral Health}

While the prevalence of smoking has decreased among the general population, it has persisted among the psychological and behavioral health population (Japuntich et al., 2018). For eight years between 2001 and 2010, the United States prevalence rate of smoking remained unchanged among those with poor psychological and behavioral health (Steinberg, Williams, \& $\mathrm{Li}, 2015)$. During these same years, the prevalence rate of smoking among those with better psychological and behavioral health decreased significantly (Steinberg et al., 2015). Approximately $40-60 \%$ of individuals with depression also smoke tobacco, $19.2-56 \%$ of individuals with anxiety smoke, and 43-80\% of individuals who abuse alcohol smoke (Michal et al., 2013). Individuals with psychological and behavioral health diagnoses reported being habitually heavy smokers. These individuals smoke more cigarettes daily than those without a psychological and behavioral health diagnosis and report having high levels of nicotine dependence (Steinberg et al., 2015). This same population reports a strong desire to achieve cessation, yet they perceive abstinence as being very difficult (Richardson, McNeill, \& Brose, 
2019). Consequently, they are less likely to achieve cessation than the general population (Burns, Strawbridge, Clancy, \& Doyle, 2017).

The increased prevalence of smoking in this population has been related to an increase in the rates of smoking initiation and a lack of smoking cessation. This rationale is supported in the literature by the low number of never smokers and/or ex-smokers in the psychological and behavioral health population (Richardson et al., 2019). There is a gap in the literature related to smoking behaviors, barriers to smoking cessation, and specific psychological and behavioral health diagnoses (Richardson et al., 2019).

\section{Smoking Behaviors and COPD}

Patients with COPD are known to have particular smoking behaviors, including a higher number of cigarettes smoked than smokers without a comorbidity. Patients with COPD also have high levels of nicotine dependence. While studying smoking characteristics of those with severe COPD who were seeking cessation treatment, researchers reported that patients with COPD smoked an average of 29.72 cigarettes daily. Participants also had a Fagerstrom Test for Nicotine Dependence score of 7.49, indicating high dependence (Jiménez Ruiz et al., 2012). This study found that additional smoking characteristics of the COPD population included a higher prevalence in males (65.6\%), advanced age (58.31), and advanced history of smoking (40.58 years). Additionally, it found that $84 \%$ of participants smoked their first cigarette within the first 30 minutes of their day (Jiménez Ruiz et al., 2012). These smoking behaviors in persons with COPD are contributing factors that makes achieving cessation a challenge (Jiménez Ruiz et al., 2012). 


\section{Smoking Behaviors in West Virginia}

Specific smoking behaviors in West Virginia are not well documented in the literature. In the Appalachian region, cigarette smoking is approximately $3.7 \%$ higher than the national average (Appalachian Regional Commission, 2017). In 2018, the highest percentage (24.7\%) of adults smoking in West Virginia came from rural settings (United Health Foundation, 2019). Those with a lower annual income also had the greatest percentage of adult smokers, with the majority at less than $\$ 50,000$ (United Health Foundation, 2019). Additionally, the highest percentage $(40.3 \%)$ of adult smokers had achieved less than a high school education (United Health Foundation, 2019).

\section{Smoking Cessation}

In the United States, nicotine dependence is the leading cause of preventable disease and death (Himelhoch, Riddle, \& Goldman, 2014). Addiction to cigarettes is measured by nicotine dependence, and differing levels of nicotine dependence affect smoking cessation success. According to the DSM-IV, nicotine withdrawal is a syndrome that has four symptoms: nicotine use immediately after waking, use of nicotine to avoid withdrawal symptoms, use of nicotine after being in a situation where it was prohibited, and waking from sleep to use nicotine (Goodwin et al., 2012). For adults, specific factors have also been identified as predictors of abstinence: “age, marital status, education level, nicotine dependence, years of smoking, previous quit attempts, prior smoking abstinence, time spent among smokers, smoking cessation motivation, stage of change, self-efficacy, social support, depressive symptoms, and psychiatric comorbidity" (Christenhusz, Pieterse, Seydel, \& van der Palen, 2007).

Numerous smoking cessation resources are available and cost effective for patients (Ho, Alnashri, Rohde, Murphy, \& Doyle, 2015). Primarily, nicotine replacement therapy (NRT) is 
used to treat nicotine withdrawal. The administration of NRT delivers low concentrations of nicotine to individuals trying to achieve cessation. It is available in many different forms, such as gum, lozenge, transdermal patch, nasal spray, and inhaler. Cessation counseling is also available for this population and predominantly targets behavioral therapy and/or motivational interviewing (Prochaska et al., 2017). Tobacco quitlines are another resource available to smokers. Tobacco quitlines are telephone services that offer both counseling and assistance with NRT. Every state in the United States has a tobacco quitline that offers these services free of charge. Only $8 \%$ of smokers trying to achieve cessation in the United States are aware of the quitline and utilize the free resource (Prochaska et al., 2017).

Current delivery of cessation resources primarily requires healthcare providers to address smoking with patients, or patients have to request smoking cessation treatment (Japuntich et al., 2018). Historically, these programs have been most effective for educated individuals and individuals without complicating factors, such as a psychological and behavioral health diagnosis (Lawrence, Hafekost, Hull, Mitrou, \& Zubrick, 2013). With time constraints during healthcare visits, smoking is often not addressed. This care delivery method has proven to be ineffective with psychological and behavioral healthcare providers, as they have the lowest cessation treatment rates among healthcare providers (Japuntich et al., 2018). In the United States, the prevalence of smoking is not evenly distributed, and disparities exist in the population (Steinberg et al., 2015).

\section{Smoking Cessation and COPD}

COPD patients are typically lifetime smokers who attempt smoking cessation multiple times without success (Christenhusz, Prenger, Pieterse, Seydel, \& van der Palen, 2012). Smoking cessation is said to be the most important factor for slowing the progression of COPD (Jonsdottir 
et al., 2015). Cessation aids in maintaining lung function in this population (Christenhusz et al., 2012). Since COPD cannot be cured, smoking cessation reduces COPD symptoms, such as sputum production and coughing. It also reduces exacerbations of COPD and improves quality of life (Christenhusz et al., 2007; Christenhusz et al., 2012).

\section{Smoking Cessation and Psychological and Behavioral Health}

A psychological and behavioral health diagnosis affects smoking cessation success. Those with a psychological and behavioral health diagnosis are considered the largest and most vulnerable subgroup among smokers (Shi, 2014). Individuals with a psychological and behavioral health diagnosis have lower cessation rates than the general population. Possible rationales for the lack of success with cessation in this population include decreased motivation, underutilization of available treatments, and greater relapse potential (Shi, 2014). Factors that have been identified as barriers to smoking cessation for those with a psychological and behavioral health diagnosis include mood irregularities, drug and alcohol use, high levels of nicotine dependence, and poor social support (El-Mallakh et al., 2016).

One study examined smoking cessation characteristics among smokers receiving psychological and behavioral health treatment. The study reported that compared to the general population, those with a psychological and behavioral diagnosis have a similar number of quit attempts. This indicates that lack of motivation may not be as significant when considering barriers. Smokers who sought psychological and behavioral health treatment were less likely to live in a smoke-free house but more likely to use cessation treatments than the general population. Nicotine replacement therapy was used frequently, but the use of counseling, quitlines, and support groups was rare. Based on this information, it could be inferred that this population needs greater social support due to their high nicotine levels. The relationship 
between smoking and a psychological and behavioral health diagnosis is prevalent in the literature; however, the relationship between psychological and behavioral health diagnoses and smoking cessation is unclear (Shi, 2014).

Historically, smoking was widely accepted in the psychological and behavioral health community (Shi, 2014). This was under the premise that nicotine was a self-medication for those with a psychological and behavioral health diagnosis which lessened psychiatric symptoms (Prochaska et al., 2017). This premise contributes to hesitation by patients and practitioners that cessation of nicotine could lead to worsened psychiatric symptoms and behavioral health outcomes. In the 1990s, fewer than $15 \%$ of patients in the outpatient psychiatric care setting were informed about cessation options (Shi, 2014).

It is now known that nicotine withdrawal mimics symptoms of psychological and behavioral health diagnoses. Nicotine withdrawal contributes to depressive symptoms, anxiety symptoms, irritability, and restlessness, all of which can be relieved by smoking (Taylor, McNeill, \& Aveyard, 2015). This physiological process deceives individuals to believe that smoking is benefiting their psychological and behavioral health. To be successful at smoking cessation, individuals need to overcome the psychological withdrawal symptoms of tobacco (Taylor et al., 2015). Once these symptoms are overcome, psychological and behavioral health does improve for the majority of individuals (Taylor et al., 2015). Individuals who achieve cessation for five years or greater report not only better psychological and behavioral health, but also better physical and overall health (Floyd, Mallow, \& Theeke, 2018). For those who do not experience improved psychological and behavioral health, research reports that there is no association between poor psychological and behavioral health post cessation and smoking relapse (Taylor et al., 2015). 
Within the last ten years, studies continued to report that smoking was not being addressed in facilities designed for psychiatric care. A study examined barriers to smoking cessation implementation in psychological and behavioral health facilities and reported that $23 \%$ of clinicians believed cessation would increase psychiatric symptoms, and $43 \%$ of clinicians reported being unsure about this outcome (Himelhoch et al., 2014). The flawed self-medication hypothesis is still identified as a substantial barrier to smoking cessation for both persons with a psychological and behavioral health diagnosis and healthcare providers (Prochaska et al., 2017).

\section{Readiness to Change}

\section{COPD}

COPD is the third leading cause of death in the world. Predictors of mortality in the COPD poulation inculde "air-flow limitation, hypercapnia, hypoxemia, low exercise capacity, smoking habits, dyspnea, low body mass index, a high BODE (body mass index, obstruction, dyspnea, exercise capacity) index, and exposure to biomass smoke” (Lou et al., 2014). Approximately one third of persons with COPD continue to smoke, yet smoking is identified for causing $80 \%$ of COPD deaths (Hilberink, Jacobs, Bottema, de Vries, \& Grol, 2005; Ho et al., 2015). In smokers, the highest incidence of COPD (35.5\%) was found in those who smoke continously, whereas the incidence of COPD in those who never smoked is only $7.8 \%$ (Lou et al., 2014). Similiarly, in a sample of COPD patients, $24.8 \%$ reported being every day smokers, $7.7 \%$ reported being some day smokers, and $42.7 \%$ reported being former smokers. However, in this sample, the percentage of never smokers with COPD was higher at $24.8 \%$ (Floyd et al., 2018).

In the COPD population, motivation to achieve smoking cessation is related to smoking behaviors. The more years patients smoke, the less motivated they are to quit. The more 
cigarettes they smoke in a day, the more motivated they are to quit (Bjarnason, Mikkelsen, \& Tønnesen, 2010). It is assumed that patients who smoke fewer cigarettes are dependent on those few cigarettes and are less likely to achieve abstinence (Christenhusz et al., 2007). Perception of their disease also contributes to their lack of cessation. A lack of knowledge related to the harmful effects of smoking and its relation to COPD serves as a barrier to smoking cessation treatment (Bjarnason et al., 2010).

A study on individualized counseling for patients with early COPD found four predictors of cessation. Cessation was statitically significant with age, body mass index (BMI), attitude, and pharmacotherapy. If smokers had a higher BMI and were older in age, they were more likely to achieve cessation. A positive attitude toward smoking cessation was also a positive predictor of cessation (Toljamo et al., 2010).

\section{Depression}

Depression affects treatment adherence and increases mortality (Lou et al., 2014). Depressed patients are three times more likely to be noncompliant with medications, diet and exercise, vaccinations, health behaviors, and medical appointments (G. Alexopoulos et al., 2016). Having depression as a comorbidity impacts patients' readiness to change. Smoking can become a coping mechanism for patients with depression; therefore, patients with depressive symptoms consistently have a reduced probability of achieving smoking cessation (Lou et al., 2014). Individuals with depression are typically lifetime smokers and smoke more cigarettes than those without depression (Michal et al., 2013). A study looking at psychological and behavioral health diagnoses and smoking status in a community found that each cigarette smoked per day increased the likelihood of developing depression by 3\% (Michal et al., 2013). There is a negative association between depressive symptoms and smoking cessation (Ho et al., 2015). 


\section{COPD and Depression}

The COPD population is not homogeneous. A common comorbidity of COPD is depression. Compared to other chronic diseases, the prevalence of depression is higher in the COPD population (Matte et al., 2016). Smoking, COPD, and depression are interrelated (Matte et al., 2016). COPD and depression share common symptoms, such as poor sleep patterns, lack of interest in life, decreased energy level, and decreased physical activity (Matte et al., 2016). In the COPD population, the prevalence of depression is estimated at $40 \%$; however, depression is missed by practitioners in approximately $50 \%$ of patients, and only $40 \%$ of those diagnosed with depression receive treatment (Yohannes et al., 2011).

The relationship between COPD and depression is bidirectional. The diagnosis of COPD causes individuals to experience increased stress levels (Bratek et al., 2015). Patients with COPD often experience differing forms of loss and social isolation as a result of their disease (Lou et al., 2014; Matte et al., 2016). COPD increases the risk of developing depression, and depression increases the risk of developing COPD (Matte et al., 2016). Depression affects initiation and maintenance of smoking, and smoking causes COPD. However, few studies report the relationship between depression and smoking status in respiratory patients (Ho et al., 2015).

One study found that $72 \%$ of patients with a diagnosis of COPD and depression refused antidepressant medications (Alexopoulos et al., 2014). Due to the stigma, many psychiatric patients deny their psychiatric diagnosis (Bratek et al., 2015). The highest rates of depression in the COPD population are commonly seen in those post-exacerbation or those requiring oxygen therapy. Depression is commonly correlated with COPD severity and the physical impairments and social isolation associated with COPD severity (Matte et al., 2016). 
There is a need to identify smokers in vulnerable groups within the psychological and behavioral health population. Inequalitites between those with psychological and behavioral health diagnoses and the general population will continue to grow, unless disparities in smoking prevalence are identified (Richardson et al., 2019). Patients with COPD and depression require variability in treatment. Depression affects self-management and the compliance needed for COPD treatment (Yohannes et al., 2011). Despite previously conceived beliefs, cessation does improve psychological and behavioral health (Ho et al., 2015). Factors that influence smoking behaviors and readiness to change need to be examined to address the complex healthcare needs of patients with COPD and depression. Exploring factors in this population can help develop personalized cessation interventions (Richardson et al., 2019).

\section{Theoretical Framework}

The Transtheoretical Model was created in the field of psychology by James Prochaska and Carlo DiClemente. The model emerged during a time when psychotherapy had grown into a field with more than 300 theories (Prochaska \& Velicer, 1997). Prochaska and DiClemente (1982) conducted a comparative analysis of the 18 leading therapies during that time. In their work, Prochaska and DiClemente (1982) noted that transtheoretical therapy was moving towards a model of change. They found that all the theories do not use differing change processes; instead, they suggested there were five processes of change (Prochaska \& DiClemente, 1982). It is from this original work that the ten processes of change are now conceptualized as consciousness raising, dramatic relief, self-reevaluation, environmental reevaluation, selfliberation, social liberation, counterconditioning, stimulus control, contingency/reinforcement management, and helping relationships (Prochaska \& Velicer, 1997). 
Stages of change then emerged from DiClemente and Prochaska's (1982) work on smoking behavior. DiClemente and Prochaska (1982) sought to compare the processes of change in participants who achieved cessation on their own to those who attended programs for cessation. In this study, it was found that each group went through a sequence of stages before implementing change (DiClemente \& Prochaska, 1982). This finding revealed that behavior change progresses through a series of stages (Prochaska \& Velicer, 1997). It is from this original work that the five stages are now conceptualized as precontemplation, contemplation, preparation, action, and maintenance (Prochaska \& Velicer, 1997).

The processes of change and stages of change were then integrated together (Prochaska \& DiClemente, 1982). From studying self-changers and therapy changers, it became apparent that certain processes of change were used during certain stages of change. Verbal processes of change are used more often at the beginning stages of change, whereas behavioral processes of change are used more when individuals are ready to act. Once individuals are committed to action, behavioral therapies play a more important role than verbal therapies (Prochaska \& DiClemente, 1982). These processes of change are critical in developing interventions for individuals as they progress through the stages of change (Prochaska \& Velicer, 1997).

Basic principles apply for progressing through the stages using decisional balance. When moving from precontemplation to contemplation, the benefits of change outweigh the consequences. When moving from contemplation to action, the consequences must decrease. The benefits must outweigh the consequences for action to occur. Statistical analysis shows the benefits must increase twice as much as the consequences decrease for change to occur (Prochaska \& Velicer, 1997). 


\section{How the Theory Has Been Used}

Prochaska and DiClemente (1982) created the Transtheoretical Model while studying smoking behavior. The model has been widely used to study smoking behaviors, but it has also been used to study other subjects, such as anxiety, substance abuse, eating disorders, AIDS prevention, mammography screening, pregnancy prevention, radon testing, obesity, and many more health behaviors (Prochaska \& Velicer, 1997).

\section{Smoking and The Transtheoretical Model}

It is important to know the stage distribution of certain populations. A series of studies on the smoking population supports that $40 \%$ of smokers are in the pre-contemplation stage, $40 \%$ of smokers are in the contemplation stage, and approximately $20 \%$ of smokers are in the preparation stage. This distribution contributes evidence that action-oriented programs are not efficient for this population (Prochaska \& Velicer, 1997).

Prochaska and DiClemente (1983) tested the Transtheoretical Model on 872 participants trying to achieve cessation without seeking treatment. In this smoking population, it was found that the processes of change were rarely used in the precontemplation stage. This is a consistent finding within the Transtheoretical Model literature. It is believed that smokers in the precontemplation stage do not comprehend smoking information, they do not reevaluate themselves, they have fewer emotional responses about the consequences of smoking, and they make fewer attempts to change their atmosphere or attentiveness away from smoking. When smokers are in the contemplation stage, they are more responsive to smoking education and feedback. It is also in the contemplation stage that smokers reevaluate themselves. This reevaluation often turns into action as individuals become upset with their behavior and make a 
commitment to change. Participants then use the processes, counterconditiong, and stimuluscontrol during the action stage (Prochaska \& DiClemente, 1983).

\section{How the Theory will Guide this Study}

The core constructs of the Transtheoretical Model will guide this study. The stages of change, the processes of change, and decisional balance will be used to explore factors influencing smoking behaviors and readiness to change for patients with comorbid COPD and depression. The Transtheoretical Model assumes that the majority of at-risk populations are not ready to take action. (Prochaska \& Velicer, 1997). Patients with comorbid COPD and depression are an at-risk population. The Transtheoretical Model construct will guide knowledge development on the stage distribution of patients with COPD and depression, what processes of change they use, and how decisional balance influences their progression through the stages of change.

\section{Summary}

There is a need to recognize the changing demographics among the smoking population. Targeting subgroups and developing innovative tobacco control is of the utmost importance (Lawrence et al., 2013). The purpose of this study was to explore and describe factors influencing smoking behaviors and readiness to change in patients with comorbid COPD and depression. The purpose was developed through the research question, aims, and the theoretical framework. The research question guided the methodology that will be presented in Chapter 3 . 


\section{Chapter Three: Methods}

The purpose of this study was to explore and describe factors influencing smoking behaviors and readiness to change in patients with comorbid COPD and depression. The research design, human subject protection, sampling method, study variables, instruments, procedures/data collection, and plan for data analysis will be discussed in this chapter.

\section{Research Design}

The research question directed the methodology for inquiry (Polit \& Beck, 2017). For this study, a descriptive cross-sectional design was used to answer the question, "What are the relationships among smoking, COPD, and depression?" The following aims stemmed from the research question:

- Aim 1: To describe the characteristics of a convenience sample of people living with COPD and differing categories of depression who sought care in West Virginia.

- Aim 2: To describe the differences between people with COPD and differing categories of depression (minimal, mild, moderate, moderately severe, severe, or no depression) related to smoking behaviors and readiness to change.

- Aim 3: To explore the relationships among COPD, depression, smoking behaviors, and readiness to change.

- Aim 4: To analyze the relationships among COPD, depression, smoking behaviors, and readiness to change.

A descriptive cross-sectional design is intended to observe, describe, and record a situation while it is occurring (Polit \& Beck, 2017). Smoking behaviors and readiness to change were described for patients with COPD while comparing differing categories of depression. The aims then aided in further describing the population. 


\section{Human Subject Protection}

\section{Informed Consent}

A formal protocol was submitted to West Virginia University's Institutional Review Board (IRB) for approval. The study was classified as exempt and did not require documentation of informed consent. Participation in the study was voluntary. Participants read a cover letter and were made aware that they had the right to withdraw from the study at any point. A $\$ 10$ gift card to Walmart was used as an incentive for participation.

\section{Privacy and Confidentiality}

Privacy was ensured to the participants throughout the study. Most participants completed the survey from home, submitting it either electronically or by mail. A few participants completed the survey on a tablet device in the waiting room of their provider's office. Screen protectors were placed on the tablets to ensure privacy. Once the surveys were completed, the compiled data was deidentified to ensure confidentiality.

\section{Risks and Benefits}

Prior to conducting a study, benefits of participating in the study must outweigh the risks. Participating in this study did not interfere with the care participants received from their healthcare provider. Risks associated with this study were minimal. Potential existed that the survey questions could trigger an emotional response from the participants. If this did occur, participants were provided a referral list that included the phone numbers for WVU Family Medicine, WVU COPD Clinic, WVU Behavioral Medicine and Psychiatry, and the National Suicide Hotline.

Benefits of participating in the study included participants' satisfaction in knowing they were contributing to knowledge development. Knowledge gained from the research findings 
could benefit other individuals with COPD and depression. These findings have the potential to impact policy and the clinical management of individuals with COPD and depression. These findings can also lead to future studies aiming to improve patient outcomes for individuals with COPD and depression.

\section{Ethical Principle: Respect for Persons}

The principle of respect for persons requires permission from participants prior to engaging in research. This principle relates directly to informed consent. Informed consent includes information disclosure, voluntariness, and understanding. Respect for persons protects participants' autonomy and dignity. It also ensures that participants are able to withdraw from the study at any point, without fear of repercussions (Beauchamp, 2008; Emanuel, Wendler, \& Grady, 2008). This study was classified as exempt and did not require documentation of informed consent. Participation in the study was voluntary. Participants read a cover letter and were made aware that they had the right to withdraw from the study at any time.

\section{Ethical Principle: Beneficence}

The principle of beneficence guards each participant from harm. More specifically, the benefits of the research should be abundant while risks are minimal (Beauchamp, 2008). The risks of participating in the study were assessed and minimized. The risks associated with this study were minimal. Potential existed that the survey may stimulate an emotional response from the participants or that completing the survey may cause the participants to experience fatigue. After completing the survey, participants were provided a referral list that included the phone numbers for WVU Family Medicine, WVU COPD Clinic, WVU Behavioral Medicine and Psychiatry, and the National Suicide Hotline. Participants were made aware that they could 
withdraw from the study at any point. Benefits of participating in the study included participants' satisfaction in knowing they were contributing to knowledge development.

\section{Ethical Principle: Justice}

The principle of justice demands that the burdens and benefits of research are fairly distributed. This principle protects vulnerable populations and promotes proper selection of research participants. Justice requires researchers to select participants who are capable of bearing the burdens of research instead of targeting the same population repeatedly (Beauchamp, 2008).

Appropriate steps were taken to ensure the ethical principle of justice was not breached. The population was assessed for vulnerability. Living in a rural location, being of a lower socioeconomic class, and having minimal education are all factors that can be considered health disparities. The researcher was sensitive to the fact that these disparities could contribute to the vulnerability of this population. The scientific reason for choosing this population was due to the high prevalence of COPD in West Virginia.

\section{Sample}

This study used a convenience sample to recruit participants. This sampling method selects participants who are readily available to participate in the study (Polit \& Beck, 2017). G*Power software version 3.0.10 was used to calculate the sample size needed to adequately power the following aims: to describe the characteristics of a convenience sample of people living with COPD and differing categories of depression who sought care in West Virginia; to describe the differences between people with COPD and differing categories of depression (minimal, mild, moderate, moderately severe, severe, or no depression) related to smoking behaviors and readiness to change; to explore the relationships among COPD, depression, 
smoking behaviors, and readiness to change; and to analyze the relationships among COPD, depression, smoking behaviors, and readiness to change. In order to detect a difference between two groups with two independent means with an effect size of $d=0.5$ (medium), $\alpha=0.05$, power $=1-\beta=0.8$, a sample of $\mathrm{N}=130$ participants was needed to reach adequate power. Participants were included in the study if they were adults greater than 18 years of age, self-reported a diagnosis of COPD, self-reported being able to read English at a $6^{\text {th }}$ grade level, and self-reported being a current or former smoker. Participants were excluded from the study if they were less than 18 years of age, unable to read English at a $6^{\text {th }}$ grade level, never smoked, or did not selfreport a diagnosis of COPD.

\section{Study Variables and Instruments}

\section{Demographic Variables}

Demographic variables were collected on the population. Information collected included participants' education level, age, gender, income, race, and comorbid conditions. Participants were also asked the questions, "Do you have depression?" and "Do you take medications to treat depression?" The variable, "Do you have depression?" will be referred to as "self-reported depression" throughout this study. The variable, "Do you take medications to treat depression?" will be referred to as "medication for depression" throughout this study.

\section{Smoking Behaviors}

Smoking behaviors are conceptually defined as patients' smoking status, frequency of use, and nicotine dependence. These smoking behaviors were measured using The Cigarette Dependence Scale (CDS-12). Participants only completed this tool if they were current smokers. The CDS-12 is a self-administered tool that provides a continuous measurement of cigarette dependence for daily and occasional cigarette smokers (Etter, Le Houezec, \& Perneger, 2003). 
The CDS-12 is a 12-item instrument. The sum of the items are calculated, and the level of cigarette dependence varies from 12 , the lowest level of dependence, to 60 , the highest level of dependence. Within the tool, participants' frequency of use is addressed by asking the question, “On average, how many cigarettes do you smoke per day?" The CDS-12 is reported to be a valid and reliable tool with psychometric testing of test-retest correlation of $>0.60$ for all items and > 0.83 overall. Internal consistency is high with Cronbach's alpha $>0.84$ (Etter et al., 2003).

\section{Readiness to Change}

Readiness to change is conceptually defined as the perceived stage, pros and cons, and situations and thoughts that occur in the processes of change that affect smoking habits. The Smoking Stage of Change Questionnaire, The Smoking Decisional Balance Questionnaire, and The Processes of Change Questionnaire were used to operationalize readiness to change.

\section{Smoking Stage of Change Questionnaire}

The perceived stage of change was measured by The Smoking Stage of Change Questionnaire, which is a three-item instrument. This questionnaire works as an algorithm, and depending on responses, participants were categorized in a stage of change. If participants had quit smoking within the last six months, they were placed in the action stage. If participants had quit more than six months ago, they were placed in the maintenance stage. If participants were thinking about quitting in the next 30 days and had one 24-hour quit attempt in the past year, they were placed in the preparation stage. If participants were thinking about quitting in the next 30 days and had no quit attempt in the past year, they were placed in the contemplation stage. If participants were thinking of quitting in the next six months, they were also placed in the contemplation stage. If participants were not thinking of quitting, they were placed in the precontemplation stage. There is no formal psychometric data to support this instrument; 
however, this instrument was specifically derived from the concepts of the Transtheoretical Model.

\section{Smoking Decisional Balance Questionnaire}

The pros and cons of smoking were measured by The Smoking Decisional Balance Questionnaire. The Smoking Decisional Balance Questionnaire is a 20-item instrument that uses a 5-point likert scale. Participants were asked to rate the importance each statement had on their decision to smoke. Selecting 1 indicated not important at all, and selecting 5 indicated extremely important. Items were added and averaged to produce two subscales, pros of smoking and cons of smoking. The difference of the scores can be calculated by subtracting the cons of smoking from the pros of smoking. If the difference is positive, the participants saw more pros of smoking. If the difference is negative, the participants saw more cons of smoking. The Smoking Decisional Balance Questionnaire is supported to be a valid and reliable tool with reliability Cronbach alphas of 0.87 (pros) and 0.90 (cons) (Velicer, DiClemente, Prochaska, \& Brandenburg, 1985).

\section{The Processes of Change Questionnaire}

The situations and thoughts that affect smoking habits were measured by The Processes of Change Questionnaire. The Processes of Change Questionnaire is a 20-item instrument. Participants were asked to rate how often the listed experiences or events had happened to them in the last month. Participants rated their responses from 1 (never) to 5 (repeatedly). The sum of all the scores gives a mean processes of change score, with a higher score indicating engagement in the processes of change. The means of the processes of change subscales were also calculated. The Processes of Change Questionnaire is a valid and reliable tool, with reliability Cronbach 
alphas of 0.69-0.92 for each of the 10 subscales (Prochaska, Velicer, DiClemente, \& Fava, 1988).

\section{COPD}

The diagnosis of COPD was initially self-reported by participants. Participants were asked if they ever received a diagnosis of COPD from a healthcare provider. If participants responded "yes," then they had COPD. If participants responded "no," then they did not have COPD. If participants were unable to answer with certainty, then they did not have COPD for this study. Due to a low response rate, other recruitment strategies were used to identify participants with COPD. Those that had a diagnosis of COPD in their electronic medical record received mailings about the research study. Also, physicians and nurse practitioners aided in identifying patients with COPD.

\section{Depression}

Depression was assessed by using the PHQ-9. The PHQ-9 is a 10-item questionnaire. Participants were asked, "Over the last two weeks, how often have you been bothered by any of the following problems?" Participants rated their responses from 0 (not at all) to 3 (nearly every day). The participants total score was then calculated, with a higher score indicating more severe depression. A score of 1-4 indicated minimal depression, a score of 5-9 indicated mild depression, a score of 10-14 indicated moderate depression, a score of 15-19 indicated moderately severe depression, and a score of 20-27 indicated severe depression. The PHQ-9 is supported to be a valid instrument with Cronbach alphas of 0.86-0.89 and test-retest reliability with a correlation of 0.84 (Kroenke, Spitzer, \& Williams, 2001). 


\section{Procedures and Data Collection}

Recruitment methods were multifaceted. Primary recruitment was first conducted face-toface at Family Medicine at WVU Medicine University Town Centre. The researcher and a research assistant approached potential participants in the waiting room with a flyer advertising the study. If patients met the inclusion criteria and elected to participate, they completed the survey via a tablet in the waiting room. Due to the COVID-19 pandemic, face-to-face recruitment occurred for one month and then was suspended.

During the COVID-19 pandemic, a study mailing was conducted from a list of COPD patients provided by Family Medicine at WVU Medicine University Town Centre. The patients received the study flyer and cover letter. Patients then contacted the researcher to participate in the study. Other recruitment strategies during this time included study advertisement through local and statewide clinics and WVU Medicine. The study flyer was placed in clinic waiting rooms, WVU's pulmonary function test lab, and WVU's emergency room waiting room. Nurse navigators, case managers, and the COPD educator at WVU Medicine were also promoting the study to patients. A newspaper advertisement for the study was also ran through the Dominion Post in Morgantown, West Virginia.

Once permitted, face-to-face recruitment resumed and was conducted at the Pulmonary Clinic at WVU Physician Office Center. COPD patients were identified by the providers and the researcher spoke to the patients after being seen by the provider. If patients met the inclusion criteria and elected to participate, they provided the researcher with their home address or email address, depending on their preference for completing the survey. A second mailing was also conducted from a list of COPD patients provided by the Pulmonary Clinic at WVU Physician Office Center. The patients received a paper copy of the survey with a prepaid return envelope. If 
patients met the inclusion criteria and elected to participate, they completed the survey and mailed it back to the researcher.

\section{Plan for Data Analysis}

Deidentified data was statistically analyzed using the Statistical Package for the Social Sciences 26 (SPSS). Prior to analyzing the data, the quality of the data was explored and cleaned based on variable type and appropriate statistical techniques to ensure accurate results.

To describe the characteristics of a convenience sample of people living with COPD and differing categories of depression who sought care in West Virginia. To describe the sample, descriptive statistics were run on the demographic variables and the PHQ-9 results. Categorical variables were analyzed by frequency distribution tables, and continuous variables were analyzed by range, means, percentiles, medians, and standard deviations.

To describe the total sample based on the key variables, descriptive statistics were run on The Cigarette Dependence Scale, The Smoking Decisional Balance Questionnaire, The Processes of Change Questionnaire, The Processes of Change Questionnaire Sub-Scales, and The Smoking Stage of Change Questionnaire. Categorical variables were analyzed by frequency distribution tables, and continuous variables were analyzed by range, means, percentiles, medians, and standard deviations.

One-way analysis of variance, chi-square test for independence, Pearson correlation, and t-tests were conducted to explore and describe the relationship among the variables based on the variable type. The researcher hypothesized that the demographic data would be similar to a sample of patients with COPD from West Virginia but different from a national sample of patients with COPD. The researcher also hypothesized that there would be at least one statistically significant covariate identified for a dependent variable. 
To describe the differences between people with COPD and differing categories of depression (minimal, mild, moderate, moderately severe, severe, or no depression) related to smoking behaviors and readiness to change. One-way analysis of variance was used to analyze The Cigarette Dependence Scale, The Smoking Decisional Balance Questionnaire, and The Processes of Change Questionnaire based on the categories of depression. Chi-square for independence was used to compare the differences between The Smoking Stage of Change Questionnaire for those with COPD only and those with COPD and depression. The researcher made the following hypotheses: participants with increased levels of depression would have a higher level of cigarette dependence and would be less ready to implement change; participants with depression would report being in the precontemplation and contemplation stage; participants without depression would report being in the contemplation and preparation stage. To explore the relationships among COPD, depression, smoking behaviors, and readiness to change. To analyze this aim, sub-aims were created.

- To describe the relationship among COPD, depression, and The Cigarette Dependence Scale. Pearson correlation was used to describe the relationships among COPD, depression severity, and The Cigarette Dependence Scale. The researcher hypothesized that participants with higher depression severity would report a higher level of cigarette dependence.

- To describe the relationship among COPD, depression, and The Smoking Decisional Balance Questionnaire. Pearson correlation was used to describe the relationships among COPD, depression severity, and The Smoking Decisional Balance Questionnaire. The researcher hypothesized that participants with higher depression severity would report more pros for smoking than cons. 
- To describe the relationship among COPD, depression, and The Processes of Change Questionnaire. Pearson correlation was used to describe the relationships among COPD, depression severity, and The Processes of Change Questionnaire. The researcher hypothesized that participants with higher depression severity would not report use of processes of change.

To analyze the relationship among COPD, depression, smoking behaviors, and readiness to change. A linear regression was used to analyze variables that had a statistically significant association among The Smoking Stage of Change Question, The Cigarette Dependence Scale, The Smoking Decisional Balance Questionnaire, and The Processes of Change Questionnaire. A multiple linear regression was used to control for key study variables if they had a significant bivariate relationship with the dependent continuous variables. No hypotheses were created due to the unknown statistical significance of the variables.

\section{Feasibility of Proposed Research}

This study was feasible due to the prevalence of COPD, smoking, and depression in the state of West Virginia. Family Medicine and the Pulmonary Clinic at WVU Medicine both treat COPD patients and offer COPD clinics. With a large portion of West Virginia residents seeking care from WVU Medicine, recruitment was deemed possible. A \$10 gift card to Walmart was also used as an incentive for patient participation.

\section{Conclusion}

To explore and describe factors influencing smoking behaviors and readiness to change in patients with comorbid COPD and depression, a descriptive cross-sectional design was used. Human subjects were protected, and the ethical principles of respect for persons, beneficence, and justice were not breached. A convenience sample was recruited, and the study variables were 
measured using valid and reliable instruments. Data collection and data analysis were then conducted to answer the research question and aims. 


\section{Chapter Four: Results}

Aim 1: To Describe the Characteristics of a Convenience Sample of People Living with COPD and Differing Categories of Depression who Sought Care in West Virginia

\section{Descriptive Statistics on Demographic Variables}

To describe the characteristics of a convenience sample of people living with COPD and differing categories of depression who sought care in West Virginia, descriptive statistics were run on the demographic variables. In this study the total sample size was 222 participants. Of the 222 participants, 108 were males (48.6\%) and 112 were females (50.5\%). Their ages ranged from 32-94 years old with a mean age of 64 years old $(\mathrm{SD}=9.6)$. Half of the sample $(50 \%)$ had an income $<\$ 24,000$, and the vast majority were white $(95 \%)$. The highest level of education completed varied among the sample, with the majority either completing high school (30.2\%) or attending some college (23\%). Diabetes mellitus (14.4\%) was the most frequent comorbid condition, followed by congestive heart failure (9\%). In this sample, 113 participants (50.9\%) stated they did not have depression, and 101 participants (45.5\%) stated they did have depression. When asked if they took medications to treat depression, 133 participants (59.9\%) reported no, and 79 participants (35.6\%) reported yes. 


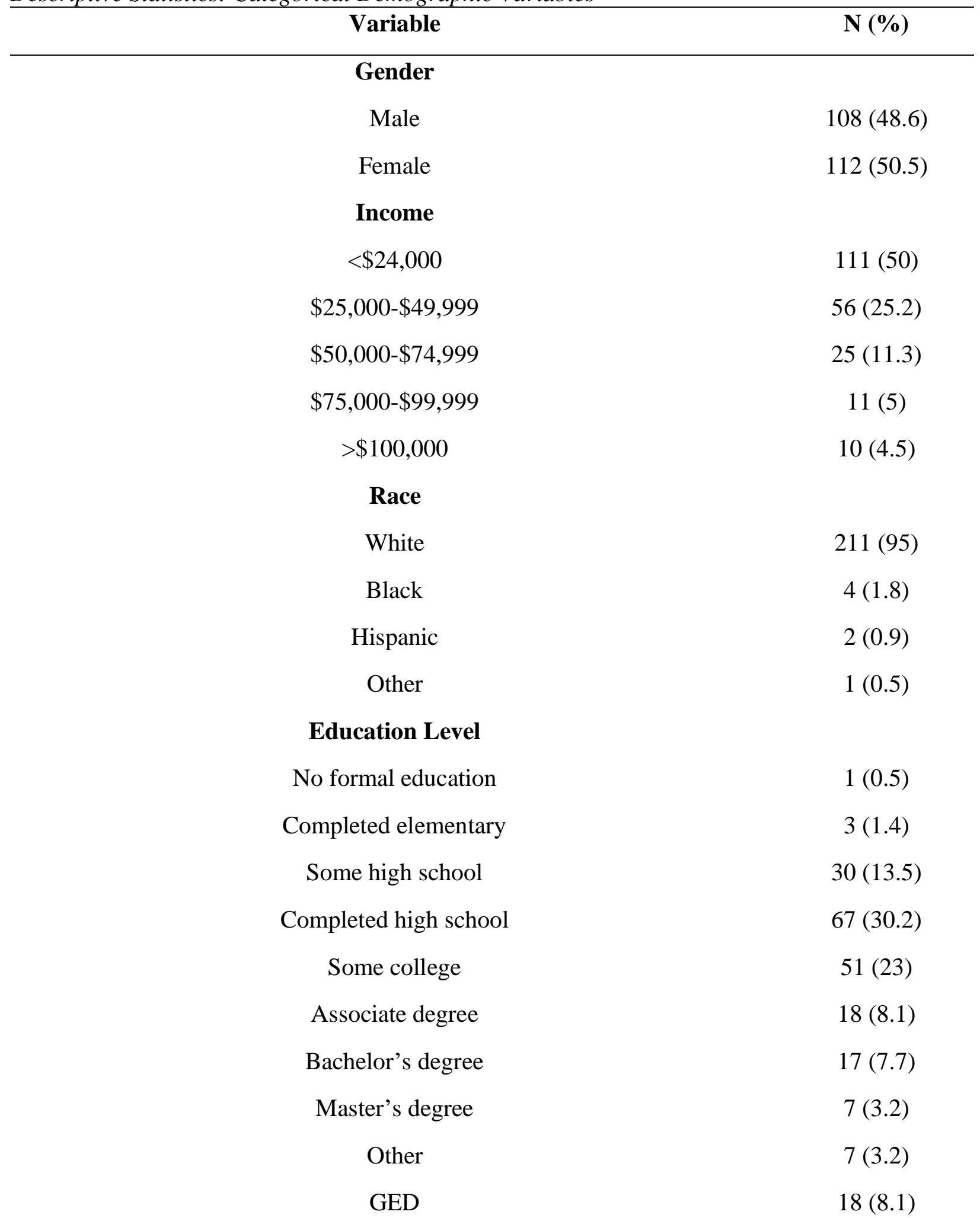




\section{Comorbid conditions}

Myocardial infarction

$17(7.7)$

Congestive heart failure

$20(9)$

Peripheral vascular disease

$18(8.1)$

Cerebral vascular accident/TIA

8 (3.6)

Dementia

$4(1.8)$

Connective tissue disease

Peptic ulcer disease

$6(2.7)$

Liver disease

$12(5.4)$

Diabetes mellitus

Hemiplegia

$1(0.5)$

Moderate to severe chronic kidney disease

$5(2.3)$

Solid tumor

Leukemia

$0(0)$

Lymphoma

$3(1.4)$

AIDS

Do you have depression?

No

$113(50.9)$

Yes

$101(45.5)$

Do you take medications to treat depression?

No

$133(59.9)$

Yes

$79(35.6)$

Descriptive Statistics: Continuous Demographic Variables

\begin{tabular}{cccc}
\hline Variable & Mean & Range & Standard Deviation \\
\hline Age & 64 & $32-94$ & 9.6 \\
\hline
\end{tabular}




\section{Descriptive Statistics on the PHQ-9}

To describe the characteristics of a convenience sample of people living with COPD and differing categories of depression who sought care in West Virginia, descriptive statistics were run on the PHQ-9 results. Depression severity ranged from 0-27, with a mean of $7.9(\mathrm{SD}=6.4)$. For this sample, 18 participants $(8.1 \%)$ were classified as having no depression, 59 participants $(26.6 \%)$ were classified as having minimal depression, 52 participants $(23.4 \%)$ were classified as having mild depression, 39 participants (17.6\%) were classified as having moderate depression, 25 participants $(11.3 \%)$ were classified as having moderately severe depression, and 12 participants (5.4\%) were classified as having severe depression.

Descriptive Statistics: $P H Q-9$

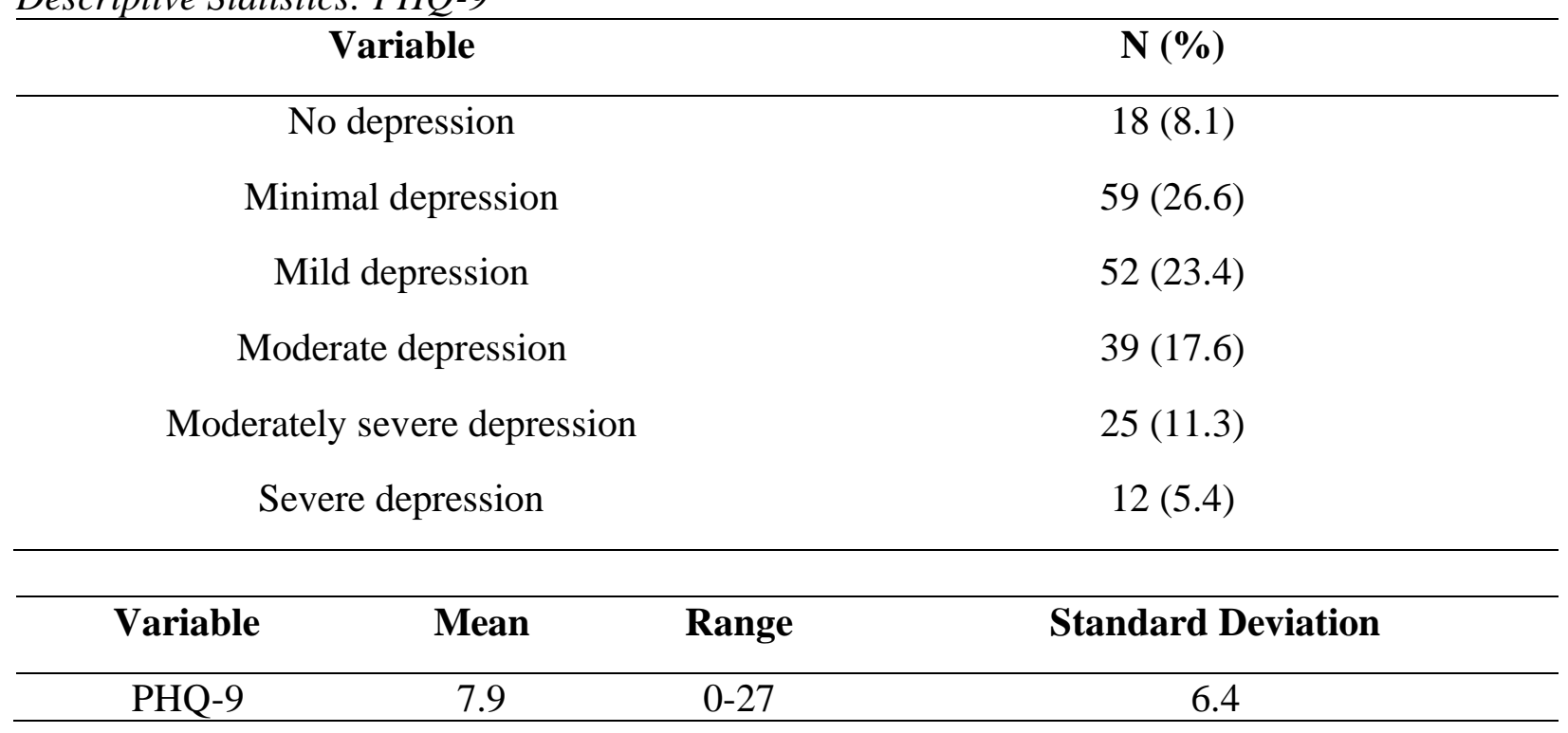

Descriptive Statistics on The Cigarette Dependence Scale, The Processes of Change

Questionnaire, The Processes of Change Questionnaire Sub-Scales, The Smoking

Decisional Balance Questionnaire, and The Smoking Stage of Change Questionnaire

To describe the characteristics of a convenience sample of people living with COPD and differing categories of depression who sought care in West Virginia, descriptive statistics were analyzed on the key study variables. Scores for The Cigarette Dependence scale ranged from 23- 
54 with a mean score of 43.82. Scores for The Processes of Change Questionnaire ranged from 19.05-88.2 with a mean score of 45.8. Scores on The Smoking Decisional Balance Questionnaire ranged from -30.4-21.4 with a mean score of -5.78. For The Processes of Change Questionnaire Sub-Scales, participants used more experiential processes (23.65) than behavioral processes (20.4). Social liberation was the most used process of change (4.72), and stimulus control was the least used (2.56).

The Smoking Stage of Change Questionnaire results found that 87 participants $(39.2 \%)$ reported they currently smoked, 4 participants $(1.8 \%)$ reported they quit within the last 6 months, 115 participants $(51.8 \%)$ reported they quit more than 6 months ago, and 2 participants $(0.9 \%)$ reported they never smoked. When asked if those who smoked were thinking of quitting, 25 participants $(11.3 \%)$ reported they wanted to quit within the next 30 days, 32 participants $(14.4 \%)$ reported they wanted to quit within the next 6 months, and 28 participants $(12.6 \%)$ reported they were not thinking of quitting.

The Smoking Stage of Change Questionnaire was also used to classify participants into their perceived stage of change. In this study, $28(12.6 \%)$ participants were in the precontemplation stage; $39(17.6 \%)$ participants were in the contemplation stage; $17(7.7 \%)$ participants were in the preparation stage; 4 participants $(1.8 \%)$ were in the action stage; and 115 $(51.8 \%)$ participants were in the maintenance stage. 
Descriptive Statistics: The Cigarette Dependence Scale, The Processes of Change Questionnaire, and The Smoking Decisional Balance Questionnaire

\begin{tabular}{cccc} 
Variable & Mean & Range & Standard Deviation \\
\hline $\begin{array}{c}\text { Cigarette } \\
\text { Dependence Scale }\end{array}$ & 43.82 & $23-54$ & 7.97 \\
$\begin{array}{c}\text { Processes of Change } \\
\text { Questionnaire }\end{array}$ & 45.8 & $19.05-88.2$ & 15.89 \\
$\begin{array}{c}\text { Smoking Decisional } \\
\text { Balance } \\
\text { Questionnaire }\end{array}$ & -5.78 & $-30.4-21.4$ & 10.81 \\
\hline
\end{tabular}

Descriptive Statistics: The Smoking Stage of Change Questionnaire

Smoking Stage of Change N (\%)

Are you a current smoker?

Yes, I currently smoke

$87(39.2)$

No, I quit within the last 6 months

$4(1.8)$

No, I quit more than 6 months ago

$115(51.8)$

No, I have never smoked

$2(0.9)$

Are you seriously thinking of quitting smoking?

Yes, within the next 30 days

25 (11.3)

Yes, within the next 6 months

32 (14.4)

No, not thinking of quitting

28 (12.6) 
Descriptive Statistics: The Smoking Stage of Change Questionnaire

\begin{tabular}{cc}
\hline Smoking Stage of Change & N (\%) \\
\hline Precontemplation & $28(12.6)$ \\
Contemplation & $39(17.6)$ \\
Preparation & $17(7.7)$ \\
Action & $4(1.8)$ \\
Maintenance & $115(51.8)$ \\
\hline
\end{tabular}

Descriptive Statistics: The Processes of Change Questionnaire Sub-Scales

\begin{tabular}{cccc}
\hline Variable & Mean & Range & $\begin{array}{c}\text { Standard } \\
\text { Deviation }\end{array}$ \\
\hline Behavioral process & 20.4 & $9.1-42.4$ & 7.96 \\
Experiential process & 23.65 & $9.1-43.3$ & 8.02 \\
Consciousness raising & 4.3 & $1.5-7.5$ & 1.77 \\
Dramatic relief & 3.48 & $1.5-7.5$ & 1.68 \\
Environmental & 3.52 & $1.5-7.5$ & 1.95 \\
reevaluation & & & 1.88 \\
Self-reevaluation & 3.48 & $1.5-7.5$ & 1.82 \\
Social liberation & 4.72 & $1.5-7.5$ & 1.86 \\
Contingency/reinforcement & 3.03 & $1.5-7.5$ & 1.67 \\
management & & & 1.97 \\
Counter conditioning & 3.43 & $1.5-7.5$ & 1.95 \\
Helping relationships & 3.66 & $1.5-7.5$ & 1.64 \\
Self-liberation & 4.06 & $1.5-7.5$ & \\
Stimulus control & 2.56 & $1.5-7.5$ & \\
\hline
\end{tabular}




\section{Education Level and The Cigarette Dependence Scale, The Processes of Change \\ Questionnaire, and The Smoking Decisional Balance Questionnaire}

To describe the characteristics of a convenience sample of people living with COPD and differing categories of depression who sought care in West Virginia, a one-way analysis of variance (ANOVA) was conducted to explore the impact of education level on The Cigarette Dependence Scale, The Smoking Decisional Balance Questionnaire, and The Processes of Change Questionnaire. For normality of the data, education categories were collapsed to "less than high school," "high school/GED," "some college," and "associate/college graduate/other." There was no significant difference at the $\mathrm{p}<0.05$ level for The Cigarette Dependence Scale F $(3,72)=0.26, p=0.85$; The Processes of Change Questionnaire $F(3,132)=2.05, p=0.11$; or The Smoking Decisional Balance Questionnaire F $(3,122)=1.03, \mathrm{p}=0.38$.

ANOVA: Impact of Education Level on The Cigarette Dependence Scale, The Processes of Change Questionnaire, and The Smoking Decisional Balance Questionnaire

\begin{tabular}{|c|c|c|c|c|c|}
\hline Variable & Df & $\begin{array}{l}\text { Sum of } \\
\text { Squares }\end{array}$ & Mean Square & $\mathrm{F}$ & $\mathrm{p}$ value \\
\hline $\begin{array}{c}\text { Cigarette } \\
\text { Dependence } \\
\text { Scale }\end{array}$ & 3 & 51.65 & 17.22 & 0.26 & 0.85 \\
\hline $\begin{array}{c}\text { Processes of } \\
\text { Change } \\
\text { Questionnaire }\end{array}$ & 3 & 1519.16 & 506.39 & 2.05 & 0.11 \\
\hline $\begin{array}{c}\text { Smoking } \\
\text { Decisional } \\
\text { Balance } \\
\text { Questionnaire }\end{array}$ & 3 & 359.78 & 119.93 & 1.03 & 0.38 \\
\hline
\end{tabular}

\section{Education Level and The Smoking Stage of Change Questionnaire}

To describe the characteristics of a convenience sample of people living with COPD and differing categories of depression who sought care in West Virginia, a chi-square test for 
independence was used to explore the differences between income and the categories of The Smoking Stage of Change Questionnaire. When asked, “Are you a current smoker?” the categories "No, I quit within the last 6 months" and "No, I have never smoked" violated the minimum cell frequency for chi-square analysis. Subsequently, the category "No, I quit within the last 6 months" was collapsed with "No, I quit more than 6 months ago" and "No, I have never smoked" was excluded from the analysis. Education categories were also collapsed to "completed high school/some college" and "college degree/other" due to violating the minimum cell frequency for chi-square analysis. The categories "no formal education," "completed elementary," and "some high school" were excluded from the analysis. A chi-square test for independence (with Yates' Continuity Correction) indicated a statistically significant association between education and the categories, "Yes, I currently smoke" and "No, I quit within the last 6 months/more than 6 months ago," $\mathrm{x}^{2}(1, \mathrm{n}=156)=4.64, \mathrm{p}=0.03$, phi $=0.02$.

When asked, "Are you seriously thinking of quitting smoking?" the categories "Yes, within the next 30 days" and "Yes, within the next 6 months" violated the minimum cell frequency for chi-square analysis. Subsequently, these categories were collapsed together. Education categories were also collapsed to "completed high school/some college" and "college degree/other" due to violating the minimum cell frequency for chi-square analysis. The categories "no formal education," "completed elementary," and some high school” were excluded from the analysis. A chi-square test for independence (with Yates' Continuity Correction) indicated no significant association between education and the categories, "Yes, within the next 30 days/6months" and "No, not thinking of quitting," $\mathrm{x}^{2}(1, \mathrm{n}=64)=0.02, \mathrm{p}=$ 0.88 , phi $=0.63$. 
Chi-Square Test for Independence: Differences Between Education Level and The Smoking Stage of Change Questionnaire

$$
\text { Smoking Stage of Change Questionnaire }
$$

\begin{tabular}{|c|c|c|}
\hline \multicolumn{3}{|c|}{ Are you a current smoker? } \\
\hline Education & Yes, I currently smoke & $\begin{array}{l}\text { No, I quit within the last } 6 \\
\text { months/more than } 6 \text { months ago }\end{array}$ \\
\hline $\begin{array}{l}\text { Completed high } \\
\text { school/some college }\end{array}$ & $52(47.7)$ & $57(52.3)$ \\
\hline College degree/other & $13(27.7)$ & $34(72.3)$ \\
\hline \multicolumn{3}{|c|}{ Are you seriously thinking of quitting smoking? } \\
\hline Education & $\begin{array}{l}\text { Yes, within the next } 30 \text { days } / 6 \\
\text { months }\end{array}$ & No, not thinking of quitting \\
\hline $\begin{array}{c}\text { Completed high } \\
\text { school/some college }\end{array}$ & $35(68.6)$ & $16(31.4)$ \\
\hline College degree/other & $8(61.5)$ & $5(38.5)$ \\
\hline
\end{tabular}

Age and The Cigarette Dependence Scale, The Processes of Change Questionnaire, and The

\section{Smoking Decisional Balance Questionnaire}

To describe the characteristics of a convenience sample of people living with COPD and differing categories of depression who sought care in West Virginia, Pearson correlation was used to describe the relationship between age and The Cigarette Dependence Scale, The Processes of Change Questionnaire, and The Smoking Decisional Balance Questionnaire. Preliminary analyses were performed to ensure no violation of the assumptions of normality, linearity, and homoscedasticity. There was a small, non-significant negative correlation between age and The Cigarette Dependence Scale, $r=-0.03, \mathrm{n}=76, \mathrm{p}=0.81$. There was a statistically significant small, negative correlation between age and The Processes of Change Questionnaire, $\mathrm{r}=-0.2, \mathrm{n}=135, \mathrm{p}=0.02$. There was a small, negative correlation between age and The Smoking Decisional Balance Questionnaire, $\mathrm{r}=-0.02, \mathrm{n}=126, \mathrm{p}=0.79$. 
Pearson Correlation: Age and The Cigarette Dependence Scale, The Processes of Change Questionnaire, and The Smoking Decisional Balance Questionnaire

\begin{tabular}{|c|c|c|c|}
\hline Variable & $\begin{array}{l}\text { Cigarette Dependence } \\
\text { Scale }\end{array}$ & $\begin{array}{l}\text { Processes of Change } \\
\text { Questionnaire }\end{array}$ & $\begin{array}{l}\text { Smoking Decisional } \\
\text { Balance } \\
\text { Questionnaire }\end{array}$ \\
\hline
\end{tabular}

\begin{tabular}{llll}
\hline Age & $-0.03, \mathrm{p}=0.81$ & $-0.2, \mathrm{p}=0.02$ & $-0.02, \mathrm{p}=0.79$ \\
\hline
\end{tabular}

\section{Age and The Smoking Stage of Change Questionnaire}

To describe the characteristics of a convenience sample of people living with COPD and differing categories of depression who sought care in West Virginia, a one-way analysis of variance (ANOVA) was conducted to explore the impact of age on The Smoking Stage of Change Questionnaire. When asked, “Are you a current smoker?” there was a statistically significant difference at the $\mathrm{p}<0.05$ level: $\mathrm{F}(3,197)=9.1, \mathrm{p}=0.00$. The effect size calculated using eta squared was 0.12. Post-hoc comparisons using the Tukey HSD test indicated that the mean score for "Yes, I currently smoke" $(\mathrm{M}=60.21, \mathrm{SD}=9.58)$ was significantly different from "No, I quit more than 6 months ago" $(\mathrm{M}=66.38, \mathrm{SD}=8.73)$. "Yes, I currently smoke" $(\mathrm{M}=$ $60.21, \mathrm{SD}=9.57)$ was also significantly different from "No, I have never smoked" $(\mathrm{M}=78, \mathrm{SD}$ $=0.00)$. "No, I quit within the last 6 months" $(\mathrm{M}=62.25, \mathrm{SD}=6.07)$ did not differ significantly from any group.

When asked, "Are you seriously thinking of quitting smoking?" the results of the ANOVA violated the assumption of homogeneity of variance $(p=0.04)$. The Robust Tests of Equality of Means indicated no significant difference $(\mathrm{p}=0.08)$. 
ANOVA: Impact of Age on The Smoking Stage of Change Questionnaire

$\begin{array}{lllll}\text { Variable } & \text { Df } & \text { Sum of } & \text { Mean Square } & \text { F }\end{array}$ Squares

\begin{tabular}{llcccc}
\hline \multicolumn{7}{c}{ Are you a current smoker? } \\
\hline Age & 3 & 2254.09 & 751.36 & 9.16 & .000 \\
\hline
\end{tabular}

Variable Df $\quad$ p value

Are you seriously thinking of quitting smoking?

Age 20.08

Gender and The Cigarette Dependence Scale, The Processes of Change Questionnaire, and The Smoking Decisional Balance Questionnaire

To describe the characteristics of a convenience sample of people living with COPD and differing categories of depression who sought care in West Virginia, t-tests were conducted to seek differences in The Cigarette Dependence Scale, The Smoking Decisional Balance Questionnaire, and The Processes of Change Questionnaire based on gender. For The Cigarette Dependence Scale, there was no significant difference in scores for males $(\mathrm{M}=44.42, \mathrm{SD}=$ 7.33 $)$ and females $(\mathrm{M}=43.28, \mathrm{SD}=8.56 ; \mathrm{t}(74)=0.62, \mathrm{p}=0.54$, two tailed $)$. For The Smoking Decisional Balance Questionnaire, there was no significant difference in scores for males $(\mathrm{M}=$ 4.21, $\mathrm{SD}=11.77)$ and females $(\mathrm{M}=-7.34, \mathrm{SD}=9.59 ; \mathrm{t}(124)=1.64, \mathrm{p}=0.1$, two tailed $)$. For The Processes of Change Questionnaire, there was a statistically significant difference in scores for males $(\mathrm{M}=41.36, \mathrm{SD}=13.82)$ and females $(\mathrm{M}=50.38, \mathrm{SD}=16.66 ; \mathrm{t}(134)=-3.44, \mathrm{p}=$ 0.00 , two tailed). 
T-Test: Differences between Gender and The Cigarette Dependence Scale, The Processes of Change Questionnaire, and The Smoking Decisional Balance Questionnaire

\begin{tabular}{ccccccc}
\hline & \multicolumn{2}{c}{ Males } & \multicolumn{5}{c}{ Females } & \\
\cline { 2 - 5 } Variables & Mean & SD & Mean & SD & t & $\mathrm{p}$ \\
\hline $\begin{array}{c}\text { Cigarette } \\
\text { Dependence } \\
\text { Scale }\end{array}$ & 44.42 & 7.33 & 43.28 & 8.56 & 0.62 & 0.54 \\
& & & & & & \\
$\begin{array}{c}\text { Processes of } \\
\text { Change } \\
\text { Questionnaire }\end{array}$ & 41.36 & 13.82 & 50.38 & 16.66 & -3.44 & 0.00 \\
& & & & & & \\
$\quad$ Smoking & -4.21 & 11.77 & -7.34 & 9.59 & 1.64 & 0.1 \\
$\begin{array}{c}\text { Decisional } \\
\text { Balance } \\
\text { Questionnaire }\end{array}$ & & & & & & \\
\hline
\end{tabular}

\section{Gender and The Smoking Stage of Change Questionnaire}

To describe the characteristics of a convenience sample of people living with COPD and differing categories of depression who sought care in West Virginia, a chi-square test for independence was used to explore the differences between categories of gender and the categories of The Smoking Stage of Change Questionnaire. When asked, "Are you a current smoker?" the categories "No, I quit within the last 6 months" and "No, I have never smoked" violated the minimum cell frequency for chi-square analysis. Subsequently, the category "No, I quit within the last 6 months" was collapsed with "No, I quit more than 6 months ago," and "No, I have never smoked" was excluded from the analysis. A chi-square test for independence (with Yates' Continuity Correction) indicated no significant association between gender and the categories, "Yes, I currently smoke" and "No, I quit within the last 6 months/more than 6 months ago, $\mathrm{x}^{2}(1, \mathrm{n}=206)=0.37, \mathrm{p}=0.54, \mathrm{phi}=0.45$. 
When asked, “Are you seriously thinking of quitting smoking?” a chi-square test for independence (with Pearson Chi-Square) indicated a statistically significant association between gender and the categories, "Yes, within the next 6 months" and "No, not thinking of quitting." For these categories, 18 males $(47.4 \%)$ reported they were not thinking of quitting, whereas 21 females $(44.7 \%)$ reported they were thinking of quitting within the next 6 months, $x^{2}(1, n=85)$ $=6.49, \mathrm{p}=0.04$, Cramer's $\mathrm{V}=0.04$.

Chi-Square Test for Independence: Differences Between Gender and The Smoking Stage of Change Questionnaire

Smoking Stage of Change Questionnaire

\begin{tabular}{ccc}
\hline \multicolumn{2}{c}{ Are you a current smoker? } \\
\hline Gender & $\begin{array}{c}\text { Yes, I currently } \\
\text { smoke }\end{array}$ & No, I quit within the last 6 months/more than \\
& $40(39.6)$ & $61(60.4)$ \\
Male & $47(44.8)$ & $58(55.2)$ \\
Female & months ago
\end{tabular}

Are you seriously thinking of quitting smoking?

\begin{tabular}{cccc}
\hline Gender & $\begin{array}{c}\text { Yes, within the next } \\
30 \text { days }\end{array}$ & $\begin{array}{c}\text { Yes, within the next } 6 \\
\text { months }\end{array}$ & $\begin{array}{c}\text { No, not thinking of } \\
\text { quitting }\end{array}$ \\
Male & $9(23.7)$ & $11(28.9)$ & $18(47.4)$ \\
Female & $16(34)$ & $21(44.7)$ & $10(21.3)$ \\
\hline
\end{tabular}

Income and The Cigarette Dependence Scale, The Processes of Change Questionnaire, and The Smoking Decisional Balance Questionnaire

To describe the characteristics of a convenience sample of people living with COPD and differing categories of depression who sought care in West Virginia, a one-way analysis of variance (ANOVA) was conducted to explore the impact of income on The Cigarette Dependence Scale, The Smoking Decisional Balance Questionnaire, and The Processes of Change Questionnaire. For normality of the data, income categories were collapsed to, 
“<\$24,000," "\$25,000-\$49,999," and " $>\$ 50,000$." There was no significant difference at the $p<$ 0.05 level for The Cigarette Dependence Scale F $(2,72)=0.15, \mathrm{p}=0.86$; The Processes of Change Questionnaire F $(2,130)=0.24, \mathrm{p}=0.79$; and The Smoking Decisional Balance Questionnaire $\mathrm{F}(2,121)=0.83, \mathrm{p}=0.44$.

ANOVA: Impact of Income on The Cigarette Dependence Scale, The Processes of Change Questionnaire, and The Smoking Decisional Balance Questionnaire

$\begin{array}{llclll}\text { Variable Df } & \begin{array}{c}\text { Sum of } \\ \text { Squares }\end{array} & \text { Mean Square } & \text { F } & \text { p value }\end{array}$

\begin{tabular}{cccccc}
\hline $\begin{array}{c}\text { Cigarette } \\
\text { Dependence } \\
\text { Scale }\end{array}$ & 2 & 20 & 10 & 0.15 & 0.86 \\
$\begin{array}{c}\text { Processes of } \\
\text { Change }\end{array}$ & 2 & 124.64 & 62.32 & 0.24 & 0.79 \\
Questionnaire & & & & & \\
$\quad$ Smoking & 2 & 196.49 & 98.24 & 0.83 & 0.44 \\
$\begin{array}{c}\text { Decisional } \\
\text { Balance }\end{array}$ & & & & & \\
Questionnaire & & & & \\
\hline
\end{tabular}

\section{Income and The Smoking Stage of Change Questionnaire}

To describe the characteristics of a convenience sample of people living with COPD and differing categories of depression who sought care in West Virginia, a chi-square test for independence was used to explore the differences between income and the categories of The Smoking Stage of Change Questionnaire. When asked, “Are you a current smoker?" the categories "No, I quit within the last 6 months" and "No, I have never smoked" violated the minimum cell frequency for chi-square analysis. Subsequently, the category "No, I quit within the last 6 months" was collapsed with "No, I quit more than 6 months ago," and "No, I have never smoked" was excluded from the analysis. Income categories were also collapsed to $<\$ 24,000$ and $>\$ 25,000$ due to violating the minimum cell frequency for chi-square analysis. A 
chi-square test for independence (with Yates' Continuity Correction) indicated a statistically significant association between income and the categories, "Yes, I currently smoke" and "No, I quit within the last 6 months/more than 6 months ago," $\mathrm{x}^{2}(1, \mathrm{n}=200)=6.93, \mathrm{p}=0.01$, phi $=$ 0.01 .

When asked, “Are you seriously thinking of quitting smoking?” A chi-square test for independence (with Pearson Chi-Square) indicated no significant association between income and the categories, "Yes, within the next 30 days," "Yes, within the next 6 months," and "No, not thinking of quitting," $\mathrm{x}^{2}(1, \mathrm{n}=85)=0.94, \mathrm{p}=0.63$, Cramer's $\mathrm{V}=0.63$.

Chi-Square Test for Independence: Differences Between Income and The Smoking Stage of Change Questionnaire

Smoking Stage of Change Questionnaire

Are you a current smoker?

\begin{tabular}{cccc}
\hline Income & $\begin{array}{c}\text { Yes, I currently } \\
\text { smoke }\end{array}$ & $\begin{array}{c}\text { No, I quit within the last } 6 \text { months/more than } \\
6 \text { months ago }\end{array}$ \\
& $54(52.4)$ & $49(47.6)$ \\
& $32(33)$ & $65(67)$ & \\
$>\$ 25,000$ & Are you seriously thinking of quitting smoking? & No, not thinking of \\
& Yes, within the next & Yes, within the next 6 & quitting \\
\hline Income & 30 days & months & $16(30.2)$ \\
& $15(28.3)$ & $22(41.5)$ & $12(37.5)$ \\
\hline$\$ 24,000$ & $10(31.3)$ & $10(31.3)$ &
\end{tabular}




\section{Race and The Cigarette Dependence Scale, The Processes of Change Questionnaire, and The Smoking Decisional Balance Questionnaire}

To describe the characteristics of a convenience sample of people living with COPD and differing categories of depression who sought care in West Virginia, t-tests were conducted to seek differences in The Cigarette Dependence Scale, The Smoking Decisional Balance Questionnaire, and The Processes of Change Questionnaire. For The Cigarette Dependence Scale, there was no significant difference in scores for "White" $(M=43.94, \mathrm{SD}=7.97)$ and "Non-White" $(\mathrm{M}=41.5, \mathrm{SD}=8.74 ; \mathrm{t}(74)=0.6, \mathrm{p}=0.55$, two tailed). For The Smoking Decisional Balance Questionnaire, there was no significant difference in scores for "White" $(\mathrm{M}=$ $-5.89, \mathrm{SD}=11.08)$ and "Non-White" $(\mathrm{M}=-2.71, \mathrm{SD}=5.67 \mathrm{t}(122)=-0.75, \mathrm{p}=0.45$, two tailed). For The Processes of Change Questionnaire, there was no significant difference in scores for "White" $(\mathrm{M}=45.88, \mathrm{SD}=16.12)$ and "Non-White" $(\mathrm{M}=44.31, \mathrm{SD}=14.08$; $\mathrm{t}(132)=0.21$, $\mathrm{p}=0.83$, two tailed).

T-Test: Differences between Race and The Cigarette Dependence Scale, The Processes of Change Questionnaire, and The Smoking Decisional Balance Questionnaire

\begin{tabular}{ccccccc}
\hline & \multicolumn{2}{c}{ White } & \multicolumn{5}{c}{ Non-white } & \multirow{2}{*}{ Variables } \\
\cline { 2 - 5 } & Mean & SD & Mean & SD & t & p \\
\hline $\begin{array}{c}\text { Cigarette } \\
\text { Dependence } \\
\text { Scale }\end{array}$ & 43.94 & 7.97 & 41.5 & 8.74 & 0.6 & 0.55 \\
$\begin{array}{c}\text { Processes of } \\
\text { Change }\end{array}$ & 45.88 & 16.12 & 44.31 & 14.08 & 0.21 & 0.83 \\
Questionnaire & & & & & & \\
$\quad \begin{array}{l}\text { Smoking } \\
\text { Decisional } \\
\text { Balance }\end{array}$ & -5.89 & 11.08 & -2.71 & 5.67 & -0.75 & 0.45 \\
Questionnaire & & & & & & \\
\hline
\end{tabular}




\section{Race and The Smoking Stage of Change Questionnaire}

To describe the characteristics of a convenience sample of people living with COPD and differing categories of depression who sought care in West Virginia, a chi-square test for independence was used to explore the differences between race and The Smoking Stage of Change Questionnaire. Due to the fact that the vast majority of participants were white, the chisquare test for independence was unable to be analyzed without violating the minimum cell frequency for chi-square analysis.

\section{Comorbid Conditions and The Cigarette Dependence Scale, The Processes of Change Questionnaire, and The Smoking Decisional Balance Questionnaire}

To describe the characteristics of a convenience sample of people living with COPD and differing categories of depression who sought care in West Virginia, a one-way analysis of variance (ANOVA) was conducted to explore the impact of comorbid conditions on The Cigarette Dependence Scale, The Smoking Decisional Balance Questionnaire, and The Processes of Change Questionnaire. Due to the small number of participants in each chronic condition, the ANOVA was unable to be analyzed.

\section{Comorbid Conditions and The Smoking Stage of Change Questionnaire}

To describe the characteristics of a convenience sample of people living with COPD and differing categories of depression who sought care in West Virginia, a chi-square test for independence was used to explore the differences between comorbid conditions and The Smoking Stage of Change Questionnaire. Due to the small number of participants in each chronic condition, the chi-square test for independence was unable to be analyzed without violating the minimum cell frequency for chi-square analysis. 


\section{Self-Reported Depression and Medication for Depression}

To describe the characteristics of a convenience sample of people living with COPD and differing categories of depression who sought care in West Virginia, a chi-square test for independence was used to explore the differences between self-reported depression and medication for depression. These categories violated the minimum cell frequency for chi-square analysis; thus, Fisher's Exact Probability test was reported. For this sample, 108 participants (98.2\%) stated they do not have depression, and do not take medications to treat depression; 2 participants (1.8\%) stated they do not have depression but take medications for depression; 25 participants $(24.8 \%)$ stated they have depression but do not take medications for depression; 76 participants (75.2\%) stated they have depression and they take medications for depression. A chi-square test for independence (with Yates' Continuity Correction) indicated a statistically significant association between self-reported depression and medication for depression, $\mathrm{x}^{2}(1, \mathrm{n}=$ 211) $=$ fisher's exact test $=0.00$.

Chi-Square Test for Independence: Differences Between Self-Reported Depression and Medication for Depression

\begin{tabular}{ccc}
\hline Variables & No, I do not take medications & Yes, I take medications \\
\hline No, I do not have depression & $108(98.2)$ & $2(1.8)$ \\
Yes, I have depression & $25(24.8)$ & $76(75.2)$ \\
\hline
\end{tabular}

\section{Self-Reported Depression and The Cigarette Dependence Scale, The Processes of Change Questionnaire, and The Smoking Decisional Balance Questionnaire}

To describe the characteristics of a convenience sample of people living with COPD and differing categories of depression who sought care in West Virginia, t-tests were conducted to seek differences in The Cigarette Dependence Scale, The Smoking Decisional Balance Questionnaire, and The Processes of Change Questionnaire based on self-reported depression. 
For The Cigarette Dependence Scale, there was a statistically significant difference in scores for "Yes, I have depression" ( $\mathrm{M}=46.03, \mathrm{SD}=7.59)$ and "No, I do not have depression" $(\mathrm{M}=$ 41.56, $\mathrm{SD}=7.88 ; \mathrm{t}(72)=2.49, \mathrm{p}=0.02$, two tailed). For the Smoking Decisional Balance Questionnaire, there was no significant difference in scores for "Yes, I have depression" (M= $5.46, \mathrm{SD}=10.29)$ and "No, $\mathrm{I}$ do not have depression" $(\mathrm{M}=-6.4, \mathrm{SD}=11.28 ; \mathrm{t}(122)=0.49, \mathrm{p}=$ 0.63, two tailed). For The Processes of Change Questionnaire, there was a statistically significant difference in scores for "Yes, I have depression" $(\mathrm{M}=49.21, \mathrm{SD}=14.3)$ and "No, I do not have depression" $(\mathrm{M}=42.75, \mathrm{SD}=17.02 ; \mathrm{t}(131)=2.36, \mathrm{p}=0.02$, two tailed $)$.

T-Test: Differences between Self-Reported Depression and The Cigarette Dependence Scale, The Processes of Change Questionnaire, and The Smoking Decisional Balance Questionnaire

\begin{tabular}{|c|c|c|c|c|c|c|}
\hline \multirow[b]{2}{*}{ Variables } & \multicolumn{2}{|c|}{ Yes, I have depression } & \multicolumn{2}{|c|}{$\begin{array}{l}\text { No, I do not have } \\
\text { depression }\end{array}$} & \multirow[b]{2}{*}{$\mathrm{t}$} & \multirow[b]{2}{*}{$\mathrm{p}$} \\
\hline & Mean & SD & Mean & SD & & \\
\hline $\begin{array}{c}\text { Cigarette } \\
\text { Dependence } \\
\text { Scale }\end{array}$ & 46.03 & 7.59 & 41.56 & 7.88 & 2.49 & 0.02 \\
\hline $\begin{array}{l}\text { Processes of } \\
\text { Change } \\
\text { Questionnaire }\end{array}$ & 49.21 & 14.3 & 42.75 & 17.02 & 2.3 & 0.02 \\
\hline $\begin{array}{c}\text { Smoking } \\
\text { Decisional } \\
\text { Balance } \\
\text { Questionnaire }\end{array}$ & -5.46 & 10.29 & -6.4 & 11.28 & 0.49 & 0.63 \\
\hline
\end{tabular}

\section{Self-Reported Depression and The Smoking Stage of Change Questionnaire}

To describe the characteristics of a convenience sample of people living with COPD and differing categories of depression who sought care in West Virginia, a chi-square test for independence was used to explore the differences between self-reported depression and the categories of The Smoking Stage of Change Questionnaire. When asked, “Are you a current 
smoker?" the categories "No, I quit within the last 6 months" and "No, I have never smoked" violated the minimum cell frequency for chi-square analysis. Subsequently, the category "No, I quit within the last 6 months" was collapsed with "No, I quit more than 6 months ago," and "No, I have never smoked" was excluded from the analysis. A chi-square test for independence (with Yates' Continuity Correction) indicated no significant association between self-reported depression and the categories, "Yes, I currently smoke" and "No, I quit within the last 6 months/more than 6 months ago," $\mathrm{x}^{2}(1, \mathrm{n}=200)=1.81, \mathrm{p}=0.18, \mathrm{phi}=-0.11$.

When asked, “Are you seriously thinking of quitting smoking?” A chi-square test for independence (with Pearson Chi-Square) indicated no significant association between selfreported depression and "Yes, within the next 30 days," "Yes, within the next 6 months," and “No, not thinking of quitting," $\mathrm{x}^{2}(1, \mathrm{n}=83)=1.46, \mathrm{p}=0.48$, Cramer's $\mathrm{V}=0.133$.

Chi-Square Test for Independence: Differences Between Self-Reported Depression and The Smoking Stage of Change Questionnaire

Smoking Stage of Change Questionnaire

Are you a current smoker?

\begin{tabular}{|c|c|c|c|}
\hline Depression & $\begin{array}{l}\text { Yes, I currently } \\
\text { Smoke }\end{array}$ & \multicolumn{2}{|c|}{$\begin{array}{l}\text { No, I quit within the last } 6 \text { months/more than } \\
\qquad 6 \text { months ago }\end{array}$} \\
\hline $\begin{array}{l}\text { No, I do not have } \\
\text { depression }\end{array}$ & $39(38.5)$ & \multicolumn{2}{|c|}{$65(62.5)$} \\
\hline $\begin{array}{l}\text { Yes, I have } \\
\text { depression }\end{array}$ & $46(47.9)$ & \multicolumn{2}{|c|}{$50(52.1)$} \\
\hline \multicolumn{4}{|c|}{ Are you seriously thinking of quitting smoking? } \\
\hline Depression & $\begin{array}{l}\text { Yes, within the next } \\
30 \text { days }\end{array}$ & $\begin{array}{c}\text { Yes, within the next } 6 \\
\text { months }\end{array}$ & $\begin{array}{c}\text { No, not thinking of } \\
\text { quitting }\end{array}$ \\
\hline $\begin{array}{l}\text { No, I do not have } \\
\text { depression }\end{array}$ & $13(34.2)$ & $12(31.6)$ & $13(34.2)$ \\
\hline $\begin{array}{l}\text { Yes, I have } \\
\text { depression }\end{array}$ & $12(26.7)$ & $20(44.4)$ & $13(28.9)$ \\
\hline
\end{tabular}




\section{Medication for Depression and The Cigarette Dependence Scale, The Processes of Change Questionnaire, and The Smoking Decisional Balance Questionnaire}

To describe the characteristics of a convenience sample of people living with COPD and differing categories of depression who sought care in West Virginia, t-tests were conducted to seek differences in The Cigarette Dependence Scale, The Smoking Decisional Balance Questionnaire, and The Processes of Change Questionnaire based on medication for depression. For The Cigarette Dependence Scale, there was no significant difference in scores for "Yes, I take medications to treat depression" $(\mathrm{M}=45.82, \mathrm{SD}=7.54)$ and "No, I do not take medications to treat depression" $(\mathrm{M}=42.23, \mathrm{SD}=8.2 ; \mathrm{t}(71)=1.93, \mathrm{p}=0.06$, two tailed $)$. For The Smoking Decisional Balance Questionnaire, there was no significant difference in scores for "Yes, I take medications to treat depression" $(\mathrm{M}=-5.43, \mathrm{SD}=10.59)$ and "No, I do not take medications to treat depression" $(\mathrm{M}=-6.51, \mathrm{SD}=10.85 \mathrm{t}(121)=0.55, \mathrm{p}=0.59$, two tailed $)$. For The Processes of Change Questionnaire, there was no significant difference in scores for "Yes, I take medications to treat depression" $(\mathrm{M}=48.19, \mathrm{SD}=12.87)$ and "No, I do not take medications to treat depression" $(\mathrm{M}=44.15, \mathrm{SD}=17.81 ; \mathrm{t}(130.56)=1.52, \mathrm{p}=0.13$, two tailed $)$. 
T-Test: Differences between Medication for Depression and The Cigarette Dependence Scale, The Processes of Change Questionnaire, and The Smoking Decisional Balance Questionnaire

Yes, I take medications No, I do not take
medications

\begin{tabular}{ccccccc} 
Variables & Mean & SD & Mean & SD & $\mathrm{t}$ & $\mathrm{p}$ \\
\cline { 2 - 5 } $\begin{array}{c}\text { Cigarette } \\
\text { Dependence } \\
\text { Scale }\end{array}$ & 45.82 & 7.54 & 42.23 & 8.2 & 1.93 & 0.06 \\
$\begin{array}{c}\text { Processes of } \\
\text { Change }\end{array}$ & 48.19 & 12.87 & 44.15 & 17.81 & 1.52 & 0.13 \\
Questionnaire & & & & & & \\
Smoking & -5.43 & 10.59 & -6.51 & 10.85 & 0.55 & 0.59 \\
$\begin{array}{c}\text { Decisional } \\
\text { Balance }\end{array}$ & & & & & & \\
Questionnaire & & & & & \\
\hline
\end{tabular}

\section{Medication for Depression and The Smoking Stage of Change Questionnaire}

To describe the characteristics of a convenience sample of people living with COPD and differing categories of depression who sought care in West Virginia, a chi-square test for independence was used to explore the differences between medication for depression and the categories of The Smoking Stage of Change Questionnaire. When asked, “Are you a current smoker?" the categories "No, I quit within the last 6 months" and "No, I have never smoked" violated the minimum cell frequency for chi-square analysis. Subsequently, the category "No, I quit within the last 6 months" was collapsed with "No, I quit more than 6 months ago," and "No, I have never smoked" was excluded from the analysis. A chi-square test for independence (with Yates' Continuity Correction) indicated a statistically significant association between medication for depression and the categories, "Yes, I currently smoke" and "No, I quit within the last 6 months/more than 6 months ago," $\mathrm{x}^{2}(1, \mathrm{n}=199)=5.39, \mathrm{p}=0.02$, phi $=0.01$. 
When asked, “Are you seriously thinking of quitting smoking?” A chi-square test for independence (with Pearson Chi-Square) indicated no significant association between medication for depression and "Yes, within the next 30 days," "Yes, within the next 6 months," and "No, not thinking of quitting," $\mathrm{x}^{2}(1, \mathrm{n}=82)=0.97, \mathrm{p}=0.62$, Cramer's $\mathrm{V}=0.62$.

Chi-Square Test for Independence: Differences Between Medication for Depression and The Smoking Stage of Change Questionnaire

\section{Smoking Stage of Change Questionnaire}

\begin{tabular}{|c|c|c|c|}
\hline \multicolumn{4}{|c|}{ Are you a current smoker? } \\
\hline Medications & $\begin{array}{l}\text { Yes, I currently } \\
\text { Smoke }\end{array}$ & \multicolumn{2}{|c|}{$\begin{array}{l}\text { No, I quit within the last } 6 \text { months/more than } \\
\qquad 6 \text { months ago }\end{array}$} \\
\hline $\begin{array}{l}\text { No, I do not take } \\
\text { medications }\end{array}$ & $44(35.5)$ & \multicolumn{2}{|c|}{$80(64.5)$} \\
\hline $\begin{array}{l}\text { Yes, I take } \\
\text { medications }\end{array}$ & $40(53.3)$ & \multicolumn{2}{|c|}{$35(46.7)$} \\
\hline \multicolumn{4}{|c|}{ Are you seriously thinking of quitting smoking? } \\
\hline Medications & $\begin{array}{l}\text { Yes, within the next } \\
30 \text { days }\end{array}$ & $\begin{array}{l}\text { Yes, within the next } 6 \\
\text { months }\end{array}$ & $\begin{array}{c}\text { No, not thinking of } \\
\text { quitting }\end{array}$ \\
\hline $\begin{array}{l}\text { No, I do not take } \\
\text { medications }\end{array}$ & $15(34.9)$ & $15(34.9)$ & $13(30.2)$ \\
\hline $\begin{array}{l}\text { Yes, I take } \\
\text { medications }\end{array}$ & $10(25.6)$ & $17(43.6)$ & $12(30.8)$ \\
\hline
\end{tabular}


Aim 2: To Describe the Differences Between People with COPD and Differing Categories

of Depression (Minimal, Mild, Moderate, Moderately Severe, Severe, or No Depression)

Related to Smoking Behaviors and Readiness to Change

Depression Severity and The Cigarette Dependence Scale, The Processes of Change

Questionnaire, and The Smoking Decisional Balance Questionnaire

To describe the differences between people with COPD and differing categories of depression (minimal, mild, moderate, moderately severe, severe, or no depression) related to smoking behaviors and readiness to change, an ANOVA was used to compare the means of The Cigarette Dependence Scale, The Processes of Change Questionnaire, and The Smoking Decisional Balance Questionnaire. For normality of the data, depression categories were collapsed to "none/minimal depression," "mild/moderate depression," and "moderately severe/severe depression." There was no significant difference at the $p<0.05$ level for The Cigarette Dependence Scale F $(2,66)=2.7, \mathrm{p}=0.08$ and The Processes of Change Questionnaire $\mathrm{F}(2,123)=2.88, \mathrm{p}=0.06$. There was a statistically significant difference at the $\mathrm{p}$ $<0.05$ for The Smoking Decisional Balance Questionnaire F $(2,112)=5.3, p=0.01$, where those with mild and moderate depression saw more cons to smoking in comparison to those with none/minimal depression and moderately severe/severe depression. 
ANOVA: Depression Severity and The Cigarette Dependence Scale, The Processes of Change Questionnaire, and The Smoking Decisional Balance Questionnaire

$\begin{array}{llllll}\text { Variable } & \text { Df } & \text { Sum of } & \text { Mean Square } & F & p \text { value }\end{array}$

Squares

\begin{tabular}{cccccc}
\hline $\begin{array}{c}\text { Cigarette } \\
\text { Dependence } \\
\text { Scale }\end{array}$ & 2 & 332.25 & 166.13 & 2.7 & 0.08 \\
$\begin{array}{c}\text { Processes of } \\
\text { Change } \\
\text { Questionnaire }\end{array}$ & 2 & 1441.11 & 720.56 & 2.88 & 0.06 \\
$\begin{array}{c}\text { Smoking } \\
\text { Decisional } \\
\text { Balance }\end{array}$ & 2 & 1137.54 & 568.77 & 5.3 & 0.01 \\
Questionnaire & & & & & \\
\hline
\end{tabular}

\section{Depression Severity and The Smoking Stage of Change Questionnaire}

To describe the differences between people with COPD and differing categories of depression (minimal, mild, moderate, moderately severe, severe, or no depression) related to smoking behaviors and readiness to change, a chi-square test for independence was used to compare the differences between The Smoking Stage of Change Questionnaire and the PHQ-9 results. Due to the small number of participants that did not have depression, the chi-square test for independence was unable to be analyzed without violating the minimum cell frequency for chi-square analysis.

Aim 3: To Explore the Relationships among COPD, Depression, Smoking Behaviors, and Readiness to Change

Sub-Aim 3a: To Describe the Relationships among COPD, Depression, and The Cigarette Dependence Scale.

To describe the relationships among COPD, depression, and The Cigarette Dependence Scale, Pearson correlation was used with the PHQ-9 results. Preliminary analyses were 
performed to ensure no violation of the assumptions of normality, linearity, and homoscedasticity. There was a statistically significant medium, positive correlation between the two variables, $r=0.32, n=74, p=0.01$, with high levels of cigarette dependence associated with more severe depression.

Sub-Aim 3b: To Describe the Relationships among COPD, Depression, and The Smoking Decisional Balance Questionnaire.

To describe the relationships among COPD, depression, and The Smoking Decisional Balance Questionnaire, Pearson correlation was used with the PHQ-9 results. Preliminary analyses were performed to ensure no violation of the assumptions of normality, linearity, and homoscedasticity. There was a small, non-significant negative correlation between the two variables, $\mathrm{r}=-0.02, \mathrm{n}=121, \mathrm{p}=0.85$, with high levels of depression associated with the patient endorsing more cons for smoking.

Sub-Aim 3c: To Describe the Relationships among COPD, Depression, and The Processes of Change Questionnaire

To describe the relationships among COPD, depression, and The Processes of Change Questionnaire, Pearson correlation was used with the PHQ-9 results. Preliminary analyses were performed to ensure no violation of the assumptions of normality, linearity, and homoscedasticity. There was a statistically significant small, positive correlation between the two variables, $r=0.26, n=132, p=0.00$, with high use of the processes of change associated with more severe depression. 
Pearson Correlation: PHQ-9 and The Cigarette Dependence Scale, The Processes of Change Questionnaire, and The Smoking Decisional Balance Questionnaire

\begin{tabular}{llll}
\hline Variable & $\begin{array}{l}\text { Cigarette Dependence } \\
\text { Scale }\end{array}$ & $\begin{array}{l}\text { Processes of Change } \\
\text { Questionnaire }\end{array}$ & $\begin{array}{l}\text { Smoking Decisional } \\
\text { Balance } \\
\text { Questionnaire }\end{array}$ \\
\hline PHQ-9 & $0.32, \mathrm{p}=0.01$ & $0.26, \mathrm{p}=0.00$ & $-0.02, \mathrm{p}=0.85$ \\
\hline
\end{tabular}

\section{Aim 4: To Analyze the Relationships among COPD, Depression, Smoking Behaviors, and}

\section{Readiness to Change}

\section{COPD, Depression Severity, and The Cigarette Dependence Scale}

To analyze the relationships among COPD, depression, smoking behaviors, and readiness to change, a linear regression was used to assess the ability of one control measure (depression severity) to predict cigarette dependence (The Cigarette Dependence Scale). Preliminary analyses were conducted to ensure no violation of the assumptions of normality, linearity, multicollinearity, and homoscedasticity. The total variance explained by the model was $9 \%, \mathrm{~F}$ (1, 72) $=8.18, \mathrm{p}<0.01$.

\section{COPD, Depression Severity, and The Processes of Change Questionnaire}

To analyze the relationships among COPD, depression, smoking behaviors, and readiness to change, a linear regression was used to assess the ability of one control measure (depression severity) to predict processes of change (The Processes of Change Questionnaire). Preliminary analyses were conducted to ensure no violation of the assumptions of normality, linearity, multicollinearity, and homoscedasticity. The total variance explained by the model was $5.9 \%, \mathrm{~F}$ $(1,130)=9.19, \mathrm{p}<0.00$. 


\section{COPD, Depression Severity, and The Cigarette Dependence Scale- Controlling for Self-}

\section{Reported Depression}

To analyze the relationships among COPD, depression, smoking behaviors, and readiness to change, multiple linear regression was used to assess the ability of one control measure (PHQ9) to predict cigarette dependence (The Cigarette Dependence Scale), after controlling for selfreported depression. Preliminary analyses were conducted to ensure no violation of the assumptions of normality, linearity, multicollinearity, and homoscedasticity. Self-reported depression explained $10 \%$ of the variance in cigarette dependence. No control measures were statistically significant, with self-reported depression recording a higher beta value (beta $=2.94$, $\mathrm{p}=0.17)$ than PHQ-9 (beta $=0.27, \mathrm{p}=0.09)$.

Multiple Linear Regression: COPD, Depression Severity, and The Cigarette Dependence ScaleControlling for Self-Reported Depression

\begin{tabular}{ccccc}
\hline Variable & B & SE & $95 \%$ CI & P \\
\hline PHQ-9 & 0.27 & 0.16 & $-0.05-0.58$ & 0.09 \\
$\begin{array}{c}\text { Self-reported } \\
\text { depression }\end{array}$ & 2.94 & 2.12 & $-1.28-7.16$ & 0.17 \\
\hline
\end{tabular}

\section{COPD, Depression Severity, and The Processes of Change Questionnaire- Controlling for}

\section{Self-Reported Depression, Gender, and Age}

To analyze the relationships among COPD, depression, smoking behaviors, and readiness to change, multiple linear regression was used to assess the ability of one control measure (PHQ9) to predict processes of change (The Processes of Change Questionnaire), after controlling for self-reported depression. Preliminary analyses were conducted to ensure no violation of the assumptions of normality, linearity, multicollinearity, and homoscedasticity. Self-reported depression explained $6.3 \%$ of the variance in processes of change. No control measures were 
statistically significant, with self-reported depression recording a higher beta value (beta $=3.95$, $\mathrm{p}=0.25)$ than PHQ-9 $($ beta $=0.47, \mathrm{p}=0.08)$.

Multiple Linear Regression: COPD, Depression Severity, and The Processes of Change Questionnaire - Controlling for Self-Reported Depression

\begin{tabular}{ccccc}
\hline Variable & B & SE & $95 \%$ CI & P \\
\hline PHQ-9 & 0.47 & 0.26 & $-0.06-0.99$ & 0.08 \\
$\begin{array}{c}\text { Self-reported } \\
\text { depression }\end{array}$ & 3.95 & 3.4 & $-2.79-10.68$ & 0.25 \\
\hline
\end{tabular}

To analyze the relationships among COPD, depression, smoking behaviors, and readiness to change, multiple linear regression was used to assess the ability of one control measure (PHQ9) to predict processes of change (The Processes of Change Questionnaire), after controlling for gender. Preliminary analyses were conducted to ensure no violation of the assumptions of normality, linearity, multicollinearity, and homoscedasticity. Gender explained $12 \%$ of the variance in processes of change. Two control measures were statistically significant, with gender recording a higher beta value $($ beta $=8.32, \mathrm{p}=0.00)$ than PHQ-9 (beta $=0.5, \mathrm{p}=0.02)$.

Multiple Linear Regression: COPD, Depression Severity, and The Processes of Change Questionnaire - Controlling for Gender

\begin{tabular}{ccccc}
\hline Variable & B & SE & $95 \%$ CI & P \\
\hline PHQ-9 & 0.5 & 0.21 & $0.08-0.9$ & 0.02 \\
Gender & 8.32 & 2.67 & $3.03-13.6$ & 0.00 \\
\hline
\end{tabular}

To analyze the relationships among COPD, depression, smoking behaviors, and readiness to change, multiple linear regression was used to assess the ability of one control measure (PHQ9) to predict processes of change (The Processes of Change Questionnaire), after controlling for age. Preliminary analyses were conducted to ensure no violation of the assumptions of normality, linearity, multicollinearity, and homoscedasticity. Age explained $7.1 \%$ of the variance in 
processes of change. One control measure was statistically significant, with the PHQ-9 recording a higher beta value (beta $=0.51, \mathrm{p}=0.03)$ than age $($ beta $=-0.24, \mathrm{p}=0.11)$.

Multiple Linear Regression: COPD, Depression Severity, and The Processes of Change Questionnaire - Controlling for Age

\begin{tabular}{ccccc}
\hline Variable & B & SE & $95 \%$ CI & P \\
\hline PHQ-9 & 0.51 & 0.23 & $0.06-0.95$ & 0.03 \\
Age & -0.24 & 0.15 & $-0.53-0.05$ & 0.11 \\
\hline
\end{tabular}




\section{Chapter Five: Findings}

\section{Aim 1: To Describe the Characteristics of a Convenience Sample of People Living with COPD and Differing Categories of Depression who sought care in West Virginia}

\section{Descriptive Statistics on Participant Characteristics}

The characteristics of a convenience sample of people living with COPD and differing categories of depression who sought care in West Virginia aligned with the demographics of the state. The findings related to gender, race, age, and income support the hypothesis that the demographic data from this study would be similar to a sample of COPD patients from West Virginia. In the state, females have a higher prevalence of COPD at $16.6 \%$, in comparison to males at 14\% (American Lung Association, 2020). In West Virginia, 93.6\% of the population is white, and COPD is found to be prevalent in West Virginia residents ages 55-64, who have an income of less than $\$ 15,000$ (West Virginia Department of Health and Human Resources, 2021).

The findings related to education in this study are characteristic of West Virginia residents. The vast majority of residents graduate from high school (86.9\%), and few residents receive a college education (20.6\%) (United States Census Bureau, 2019). The prevalence of diabetes and congestive heart failure in the sample aligned with the prevalence of these diseases in the state. West Virginia ranks first in the nation for cardiovascular disease and second in the nation for diabetes (West Virginia Department of Health and Human Resources, 2021). The percentage of adults that report depression in West Virginia is 28.8\% (United Health Foundation, 2021). In comparison to the findings of this study, this indicates that the prevalence of depression is higher among a sample of patients with COPD (45.5\%). These findings help identify sociodemographic factors that are characteristic for patients with comorbid COPD and depression who seek care in West Virginia. 
The hypothesis that the demographic data from this study would be different from demographic data from a national sample of COPD patients was rejected. It is known that COPD is more prevalent in individuals that have a lower income, and psychological distress is reported in $42.8 \%$ of COPD patients (American Lung Association, 2020). In a national sample of patients that self-reported COPD, the majority of participants were white women, 65 years and older; were of low income; and attended one year or more of college (Floyd et al., 2018). These characteristics are similar to those with COPD and depression who sought care in West Virginia. Understanding these sociodemographic factors, such as education level, the presence of multiple chronic conditions, and high rates of depression, are important in clinical practice for the successful management of patients with COPD, especially those with comorbid depression.

\section{Descriptive Statistics on the PHQ-9, Self-Reported Depression, and Medication for Depression}

To describe the depression severity of this sample, the responses to the PHQ-9 were analyzed. The mean (7.9) indicated participants suffered from mild depression; however, differing categories of depression existed among the sample. Despite the 113 participants (50.9\%) who self-reported that they did not have depression, the PHQ-9 results showed that only 18 participants $(8.1 \%)$ were classified as having no depression. In the COPD population, depression often goes undiagnosed and is missed in approximately 50\% of patients (Yohannes et al., 2011). In this sample, it can be said that depression was under-diagnosed in $38.8 \%$ of the participants. This finding highlights the need for continual depression screening in clinical practice using validated clinical screening tools for individuals living with COPD.

To describe the characteristics of the sample, medication use for depression was analyzed. Differing categories of depression require variability in treatment. When the PHQ-9 is 
used in clinical practice, pharmacotherapy is a proposed treatment option when a patient scores a severity of depression as moderate or greater (Patient-Centered Primary Care Collaborative, 2019). In this population, $34.3 \%$ could benefit from pharmacotherapy, which aligned with the participants' self-reported medication use (35.6\%). However, it is clear from these results that even those taking medication were still showing some level of depressive symptoms. It is estimated that $40 \%$ of patients diagnosed with depression receive adequate treatment, which accurately describes the population of this study (Yohannes et al., 2011). This finding highlights the need to verify medication adherence, assess medication effectiveness, and assess the need for adjunct treatment interventions for depression.

\section{Descriptive Statistics on The Cigarette Dependence Scale, The Processes of Change Questionnaire, The Processes of Change Questionnaire Sub-Scales, The Smoking Decisional Balance Questionnaire, and The Smoking Stage of Change Questionnaire.}

Descriptive statistics were used to describe the total sample in relation to smoking behaviors, as measured by The Cigarette Dependence Scale. Unsurprisingly, participants who smoked reported high levels of nicotine dependence. This finding is typical of the COPD population (Jiménez Ruiz et al., 2012). This finding is also typical of those with a psychological and behavioral health diagnosis (Steinberg et al., 2015). Psychological and behavioral health diagnoses, such as depression impact nicotine dependence. Patients that have depression are known to smoke more cigarettes and have higher nicotine dependence than those who do not have depression (Michal et al., 2013). This highlights the need for policies related to adequate smoking cessation tools in West Virginia, specifically for those with comorbid COPD and depression. 
Descriptive statistics were used to describe the total sample in relation to their readiness to change, as measured by The Smoking Stage of Change Questionnaire. The findings of this analysis are supported in the literature showing that one third of COPD patients continue to smoke (39.2\%) (Hilberink et al., 2005). In this sample, only $12.6 \%$ of smoking participants indicated they were not thinking of quitting. Most participants wanted to quit within the next 30 days or within the next 6 months $(25.7 \%)$. This is consistent with the belief that half of adult smokers desire to achieve cessation (Centers for Disease Control and Prevention, 2017). Patients who receive smoking cessation advice from a clinician are more likely to achieve cessation (Prochaska et al., 2017). Knowing that most COPD patients in this sample are thinking of quitting highlights the importance of assessing patients for their readiness to change in clinical practice.

The Smoking Stage of Change Questionnaire results also classified participants into their perceived stage of change. These findings support the assumption that most current smokers are not ready to act (Prochaska \& Velicer, 1997). Therefore, action-oriented smoking cessation programs are not conducive for this population. Interventions and policies aimed at increasing readiness to change are needed, especially in this population. Since most smoking cessation programs in West Virginia are action-oriented, this finding highlights the need for policy changes regarding reimbursement of smoking cessation programs that increase readiness to change in the state.

Descriptive statistics were used to describe the total sample in relation to their readiness to change, as measured by The Smoking Decisional Balance Questionnaire. These findings indicated that the sample saw more negative aspects to smoking then positives. Participants perceptions on the pros and cons of smoking are important to evaluate, as they can vary 
depending on the stage of change. In this population, a large portion of current smokers were classified as being in the contemplation stage. In this stage, individuals reflect on the positive and negative aspects of changing their behavior. Individuals can dwell in this stage, which is referred to as chronic contemplation. To prevent chronic contemplation, individuals' readiness to change must be evaluated so personalized interventions can be implemented to promote change.

The total sample was analyzed for readiness to change, as measured by The Processes of Change Questionnaire. These findings indicated that the population was engaged in various processes of change. Identifying situations and thoughts that help participants progress through the stages of change are important to develop individualized interventions (Prochaska \& Velicer, 1997). For this sample, participants used more experiential processes (23.65) than behavioral processes (20.4). This means that experiential activities were used more often than behavior activities to progress through the stages of change. Social liberation was the most used process of change (4.72). Social liberation refers to when individuals experience more alternatives or social opportunities (Prochaska \& Velicer, 1997). New opportunities and new policies that promote health are imperative to help participants move through the stages of change. This highlights the need for advocacy for health promotion opportunities and alternatives.

Consciousness raising was the second most used process of change (4.3). Consciousness raising refers to when individuals recognize the health behavior and acknowledge the consequences (Prochaska \& Velicer, 1997). These findings align with those of The Smoking Decisional Balance Questionnaire. Participants endorsed more negative aspects to smoking then positives. Participants of this study clearly recognized the health behavior, acknowledged the consequences, and continued to smoke. Hence, identifying factors that influence the decision to 
not smoke may need to be assessed along with education regarding the dangers of smoking (Prochaska \& Velicer, 1997).

Stimulus control, which is a behavioral process, was the least used process of change (2.56) among the sample. Stimulus control refers to when individuals remove unhealthy behavior cues and replace them with prompts for healthy behavior (Prochaska \& Velicer, 1997). This behavioral process is used most often during the action stage (Prochaska \& DiClemente, 1983). With few participants (1.8\%) in the action stage, this supports the belief that certain processes of change are only used during specific stages of change. Future research should be aimed at interventions that target smoking cessation specific for participants' stage of change while considering the other unique characteristics of this population, such as, gender, income, race, education, comorbid conditions, depression severity, medication use, smoking decisional balance, processes of change, and smoking behaviors.

Aim 2: To Describe the Differences Between People with COPD and Differing Categories of Depression (Minimal, Mild, Moderate, Moderately Severe, Severe, or No Depression) Related to Smoking Behaviors and Readiness to Change

Depression Severity and The Cigarette Dependence Scale, The Processes of Change Questionnaire, The Smoking Decisional Balance Questionnaire, and The Smoking Stage of Change Questionnaire

There was no difference between people who had COPD and differing categories of depression related to smoking behaviors, as measured by The Cigarette Dependence Scale ( $\mathrm{p}=$ 0.08). This was a new finding as psychological and behavioral health diagnoses are associated with higher levels of nicotine dependence (Steinberg et al., 2015). This finding rejects the 
hypothesis that participants with increased levels of depression would have a higher level of cigarette dependence.

There was no difference between people who had COPD and differing categories of depression related to readiness to change, as measured by The Processes of Change Questionnaire $(\mathrm{p}=0.06)$. There was a statistically significant difference at the $\mathrm{p}<0.05$ for people who had COPD and differing categories of depression related to readiness to change, as measured by The Smoking Decisional Balance Questionnaire. Depression severity does affect how one perceives the pros and cons of smoking. Depression causes mood irregularities, which have been identified as a barrier to cessation for patients with psychological and behavioral health diagnoses (El-Mallakh et al., 2016). This highlights the importance of adequate depression treatment for this population.

Differences between people who had COPD only and those who had COPD and depression related to readiness to change, as measured by The Smoking Stage of Change Questionnaire, were unable to be analyzed. The data was unable to be analyzed without violating the minimum cell frequency for chi-square analysis. Hypotheses related to the stages of change were unable to be evaluated. Future research should be powered adequately to address this limitation.

Differing categories of depression does impact patients' readiness to change. For COPD patients that continue to smoke, continual assessment of individuals' severity of depression is of the utmost importance. Adequate treatment of depression could improve smoking cessation rates in this population. 


\section{Aim 3: To Explore the Relationships among COPD, Depression, Smoking Behaviors, and Readiness to Change}

Sub-Aim 3a: To Describe the Relationships among COPD, Depression, and The Cigarette Dependence Scale

The relationship among COPD, depression, and smoking behaviors, as measured by The Cigarette Dependence Scale, indicated that a statistically significant medium, positive correlation exists. This finding supports the hypothesis that participants with higher depression severity would report a higher level of cigarette dependence. This finding is supported in the literature. It is well known that the prevalence of smoking is higher for those that have depression (ElMallakh et al., 2016). Those that have a psychological and behavioral health diagnoses are less likely to achieve cessation than the general population (Burns et al., 2017). A dose-response relationship between smoking and mood disorders exists (Goodwin et al., 2012) Understanding the smoking behaviors of this population is important, as smoking behaviors impact disease management and outcomes. Depression and nicotine dependence could be factors that are impacting smoking cessation in this population.

\section{Sub-Aim 3b: To Describe the Relationships among COPD, Depression, and The Smoking Decisional Balance Questionnaire}

The relationship among COPD, depression, and readiness to change, as measured by The Smoking Decisional Balance Questionnaire, indicated that a small, negative correlation exists with high levels of depression associated with the patient endorsing more cons for smoking. This finding rejects the hypothesis that participants with higher depression severity would report more pros for smoking than cons for smoking. It is apparent that participants of this study understood smoking and the negative affects smoking has on health. There may be a reciprocal relationship 
between the variables. Depression may lead to increased smoking behavior, which leads to worsening COPD and could lead to increased depression and more smoking. All of this may decrease the ability or desire to quit. Interventions aimed at treating depression instead of solely on smoking cessation seem to be warranted. Future research should examine rates of smoking cessation when depression is controlled prior to cessation interventions.

Sub-Aim 3c: To Describe the Relationships among COPD, Depression, and The Processes of Change Questionnaire

The relationship among COPD, depression, and readiness to change, as measured by The Processes of Change Questionnaire indicated that a statistically significant small, positive correlation exists, with high use of the processes of change associated with more severe depression. This rejects the hypothesis that participants with higher depression severity would not report use of processes of change. Participants with higher depression severity want to quit and want to progress through the stages of change. The Transtheoretical Model approach to behavior change enhances self-control, which is important for those with depression (Prochaska $\&$ Velicer, 1997). There is a need for personalized interventions to target the stage and promote change for this population. Focusing on depression control may be the key to assisting patients through the stages of change and ultimately improving cessation rates and COPD outcomes.

\section{Aim 4: To Analyze the Relationships among COPD, Depression, Smoking Behaviors and}

\section{Readiness to Change}

\section{COPD, Depression Severity, and The Cigarette Dependence Scale}

Further analysis was done to analyze the statistically significant medium, positive correlation among COPD, depression, and smoking behaviors, as measured by The Cigarette Dependence Scale. This was the first study to examine the relationship among these variables 
with a sample of participants who sought care in West Virginia. Linear regression results showed that if depression is treated, cigarette dependence could decrease for $9 \%$ of COPD patients. This emphasizes the importance of screening and treating patients with COPD for depression in clinical practice.

\section{COPD, Depression Severity, and The Processes of Change Questionnaire}

Further analysis was done to analyze the statistically significant small, positive correlation among COPD, depression, and readiness to change, as measured by The Processes of Change Questionnaire. Depression severity explained 5.9\% of the variance in the population's engagement in the processes of change. Given the possible reciprocal relationship between the variables, this finding could illustrate how participants experience chronic contemplation. Participants want to use the processes of change to progress through the stages of change; however, depression interferes with their progression. Future research should assess and treat COPD patients for depression and measure how this intervention affects patients smoking behaviors and readiness to change.

COPD, Depression Severity, and The Cigarette Dependence Scale- Controlling for Self-

\section{Reported Depression}

Further analysis was done to analyze the relationships among COPD, depression, and smoking behaviors, as measured by The Cigarette Dependence Scale, controlling for selfreported depression. This supports the hypothesis that there would be at least one statistically significant covariate identified for a dependent variable. Self-reported depression explained 10\% of the variance in cigarette dependence. However, this finding is not statistically significant. Given the PHQ-9 results, many participants did not know they had depression. Therefore, the self-reported depression findings were inaccurate. This emphasizes the need to use validated 
depression screening tools for individuals living with COPD. Future research should compare documented depression diagnoses with patients PHQ-9 results.

COPD, Depression Severity, and The Processes of Change Questionnaire- Controlling for Gender, Age, and Self-Reported Depression

Further analysis was done to analyze the relationships among COPD, depression, and readiness to change, as measured by The Processes of Change Questionnaire, controlling for the variables, gender, age, and self-reported depression. This supports the hypothesis that there would be at least one statistically significant covariate identified for a dependent variable. Age explained $7.1 \%$ of the variance in the population's engagement in the processes of change. Gender explained $12 \%$ of the variance in the population's engagement in the processes of change. Self-reported depression explained $6.3 \%$ of the variance in the population's engagement in the processes of change. Age and gender are not modifiable variables. However, depression severity can be modified. Knowing that the self-reported depression variable may not be adequately capturing true depression status, future research should be aimed at adequately assessing, diagnosing, and treating depression to determine impact on outcomes, specifically related to the processes of change.

\section{Limitations}

Limitations of the study included the descriptive cross-sectional design. Data was collected from February 2020 to November 2020. A true cause and effect relationship cannot be determined with this study design (Polit \& Beck, 2017).

Sampling was a limitation of this study. This study used a convenience sample to recruit participants, which is prone to sampling bias (Polit \& Beck, 2017). For inclusion in the study, participants self-reported a diagnosis of COPD, self-reported being able to read English at a $6^{\text {th }}$ 
grade level, and self-reported being a current or former smoker. During face-to-face recruitment at the Pulmonary Clinic, the provider verified participants' COPD diagnosis and smoking status. During other recruitment strategies, COPD diagnosis, reading level, and smoking status were not otherwise validated.

For recruitment mailings, patients that had a diagnosis of COPD in their electronic medical record received mailings. COPD is often used as an umbrella term for chronic respiratory diseases. It is possible patients had COPD listed in their electronic medical record without having pulmonary function tests to support the diagnosis. All of these factors could lead to a misrepresented sample. Generalizability of the results to West Virginia is limited, as being a West Virginia resident was not in the inclusion criteria for this study. Generalizability of the results to other geographical locations is limited due to the racial homogeneity of the sample.

There is no formal psychometric data to support The Smoking Stage of Change Questionnaire. A total processes of change score was used for data analysis. This score gives information regarding participants' overall engagement in various processes of change. It does not analyze the specific processes of change being used. Further analysis utilizing the processes of change sub-scales would be beneficial for future research.

Despite over sampling, the study was not adequately powered for all statistical analyses. Data that was received by a mailed survey was entered into RedCap by the researcher. Errors in data input may have occurred during this process. Data was also collected during the COVID-19 pandemic. For the COPD population, depression severity may have been impacted by the pandemic and the social isolation experienced during quarantine. 


\section{Conclusion}

Patients with comorbid COPD and depression require variability in treatment. Successful management of these patients includes understanding their sociodemographic factors, depression severity, smoking behaviors, and readiness to change. COPD patients need to receive continual screening and treatment for depression. Treatment for depression can improve COPD patient outcomes and aid in achieving smoking cessation. For current smokers, smoking behaviors need to be assessed to understand patients' current level of depression, smoking status, frequency of use, and nicotine dependence. To achieve cessation, the relationship between depression and readiness to change needs to be assessed to develop personalized smoking cessation interventions. Practitioners must understand patients perceived stage, pros and cons, and situations and thoughts that occur in the process of change to help achieve cessation. The relationships among smoking, COPD, and depression must be recognized to address the complex health care needs of this population. Future research should be aimed at understanding the specific link between depression and readiness to change. 


\section{References}

Alexopoulos, Kiosses, D. N., Sirey, J. A., Kanellopoulos, D., Seirup, J. K., Novitch, R. S., . . Raue, P. J. (2014). Untangling therapeutic ingredients of a personalized intervention for patients with depression and severe COPD. The American Journal of Geriatric Psychiatry, 22(11), 1316-1324. doi:10.1016/j.jagp.2013.05.006

Alexopoulos, G., Sirey, J., Banerjee, S., Kiosses, D., Pollari, C., Novitch, R., . . Raue, P. (2016). Two behavioral interventions for patients with major depression and severe COPD. The American Journal of Geriatric Psychiatry, 24(11), 964-974. doi:10.1016/j.jagp.2016.07.014

American Cancer Society Cancer Action Network. (2017). How do you measure up. Retrieved from https://www.acscan.org/sites/default/files/National\%20Documents/HDYMU2017.pdf\#page $=13$

American Lung Association. (2017). How serious is COPD. Retrieved from http://www.lung.org/lung-health-and-diseases/lung-disease-lookup/copd/learn-aboutcopd/how-serious-is-copd.html

American Lung Association. (2020). COPD Trends Brief Retrieved from https://www.lung.org/research/trends-in-lung-disease/copd-trends-brief

Appalachian Regional Commission. (2017). Health Disparities in Appalachia Retrieved from https://www.arc.gov/assets/research reports/Health Disparities in Appalachia August 2017.pdf

Beauchamp, T. (2008). The Belmont Report. In Oxford Textbook of Clinical Research Ethics. Bjarnason, N. H., Mikkelsen, K. L., \& Tønnesen, P. (2010). Smoking habits and beliefs about smoking in elderly patients with COPD during hospitalization. Journal of Smoking Cessation, 5(1), 15-21. doi:10.1375/jsc.5.1.15

Bratek, A., Zawada, K., Beil-Gawełczyk, J., Beil, S., Sozańska, E., Krysta, K., . . . Pierzchała, W. (2015). Depressiveness, symptoms of anxiety and cognitive dysfunctions in patients with asthma and chronic obstructive pulmonary disease (COPD): Possible associations with inflammation markers: A pilot study. Journal of Neural Transmission, 122(Suppl 1), 83-91. doi:10.1007/s00702-014-1171-9

Burns, A., Strawbridge, J. D., Clancy, L., \& Doyle, F. (2017). Exploring smoking, mental health and smoking-related disease in a nationally representative sample of older adults in Ireland - A retrospective secondary analysis. Journal of Psychosomatic Research, 98, 7886. doi:10.1016/j.jpsychores.2017.05.005

Centers for Disease Control and Prevention. (2017). Quitting Smoking. Retrieved from https://www.cdc.gov/tobacco/data_statistics/fact_sheets/cessation/quitting/index.htm

Centers for Disease Control and Prevention. (2018). Health Effects of Cigarette Smoking Retrieved from https://www.cdc.gov/tobacco/data statistics/fact sheets/health effects/effects cig smoki ng/index.htm

Centers for Disease Control and Prevention. (2019a). Current Cigarette Smoking Among Adults in the United States. Retrieved from https://www.cdc.gov/tobacco/data_statistics/fact_sheets/adult_data/cig_smoking/index.ht $\underline{\mathrm{m}}$ 
Centers for Disease Control and Prevention. (2019b). Economic Trends in Tobacco Retrieved from

https://www.cdc.gov/tobacco/data_statistics/fact_sheets/economics/econ_facts/index.htm

Christenhusz, Pieterse, M., Seydel, E., \& van der Palen, J. (2007). Prospective determinants of smoking cessation in COPD patients within a high intensity or a brief counseling intervention. Patient Education and Counseling, 66(2), 162-166. doi:10.1016/j.pec.2006.11.006

Christenhusz, Prenger, R., Pieterse, M. E., Seydel, E. R., \& van der Palen, J. (2012). Costeffectiveness of an intensive smoking cessation intervention for COPD outpatients. Nicotine \& Tobacco Research, 14(6), 657-663. doi:10.1093/ntr/ntr263

DiClemente, C. C., \& Prochaska, J. O. (1982). Self-change and therapy change of smoking behavior: a comparison of processes of change in cessation and maintenance. Addictive behaviors, 7(2), 133-142.

Division of Tobacco Prevention. (2018). West Virginia Tobacco Quitline. Retrieved from http://dhhr.wv.gov/wvdtp/cessation/Quitline/Pages/default.aspx

El-Mallakh, P., McPeak, D., Khara, M., \& Okoli, C. T. (2016). Smoking Behaviors and Medical Co-Morbidities in Patients With Mental Illnesses. Archives of psychiatric nursing, 30(6), 740-746. doi:10.1016/j.apnu.2016.07.003

Emanuel, E., Wendler, D., \& Grady, C. (2008). An Ethical Framework for biomedical resaerch. In the Oxford Textbook of Clinical Research Ethics.

Etter, J.-F. o., Le Houezec, J., \& Perneger, T. V. (2003). A self-administered questionnaire to measure dependence on cigarettes: The cigarette dependence scale. Neuropsychopharmacology, 28(2), 359-370.

Floyd, J., Mallow, J., \& Theeke, L. (2018). Health-related quality of life, depression, and smoking status in patients with COPD: Results from the 2016 Behavioral Risk Factor Surveillance System data Open Journal of Nursing 8, 779-794.

Goodwin, R. D., Lavoie, K. L., Lemeshow, A. R., Jenkins, E., Brown, E. S., \& Fedoronko, D. A. (2012). Depression, anxiety, and COPD: The unexamined role of nicotine dependence. Nicotine \& Tobacco Research, 14(2), 176-183. doi:10.1093/ntr/ntr165

Hilberink, S. R., Jacobs, J. E., Bottema, B. J. A. M., de Vries, H., \& Grol, R. P. T. M. (2005). Smoking cessation in patients with COPD in daily general practice (SMOCC): Six months' results. Preventive Medicine: An International Journal Devoted to Practice and Theory, 41(5-6), 822-827. doi:10.1016/j.ypmed.2005.08.003

Himelhoch, S., Riddle, J., \& Goldman, H. H. (2014). Barriers to implementing evidence-based smoking cessation practices in nine community mental health sites. Psychiatric services (Washington, D.C.), 65(1), 75-80. doi:10.1176/appi.ps.201200247

Ho, S. Y., Alnashri, N., Rohde, D., Murphy, P., \& Doyle, F. (2015). Systematic review and meta-analysis of the impact of depression on subsequent smoking cessation in patients with chronic respiratory conditions. General Hospital Psychiatry, 37(5), 399-407. doi:10.1016/j.genhosppsych.2015.05.002

Japuntich, S. J., Sherman, S. E., Joseph, A. M., Clothier, B., Noorbaloochi, S., Danan, E., . . Fu, S. S. (2018). Proactive tobacco treatment for individuals with and without a mental health diagnosis: Secondary analysis of a pragmatic randomized controlled trial. Addictive behaviors, 76, 15-19. doi:10.1016/j.addbeh.2017.07.024

Jiménez Ruiz, C. A., Pinedo, A. R., Guerrero, A. C., Uibarri, M. M., Fernández, M. C., \& Gonzalez, G. L. (2012). Characteristics of COPD smokers and effectiveness and safety of 
smoking cessation medications. Nicotine \& Tobacco Research, 14(9), 1035-1039. doi:10.1093/ntr/nts001

Jonsdottir, H., Amundadottir, O. R., Gudmundsson, G., Halldorsdottir, B. S., Hrafnkelsson, B., Ingadottir, T. S., . . . Stefansdottir, I. K. (2015). Effectiveness of a partnership-based selfmanagement programme for patients with mild and moderate chronic obstructive pulmonary disease: A pragmatic randomized controlled trial. Journal of Advanced Nursing, 71(11), 2634-2649. doi:10.1111/jan.12728

King, J. L., Reboussin, B. A., Spangler, J., Cornacchione Ross, J., \& Sutfin, E. L. (2018). Tobacco product use and mental health status among young adults. Addictive behaviors, 77, 67-72. doi:10.1016/j.addbeh.2017.09.012

Kroenke, K., Spitzer, R. L., \& Williams, J. B. W. (2001). The PHQ-9 : Validity of a brief depression severity measure. Journal of General Internal Medicine, 16(9), 606-613. doi:10.1046/j.1525-1497.2001.016009606.x

Lawrence, D., Hafekost, J., Hull, P., Mitrou, F., \& Zubrick, S. R. (2013). Smoking, mental illness and socioeconomic disadvantage: analysis of the Australian National Survey of Mental Health and Wellbeing. BMC Public Health, 13(1), 1-20. doi:10.1186/1471-2458$13-462$

Lee, J., Park, J., Kim, H., \& Shin, H. (2014). Smoking behaviors among people with disabilities in Korea. Disability and Health Journal, 7(2), 236-241. doi:10.1016/j.dhjo.2013.11.002

Lou, P., Chen, P., Zhang, P., Yu, J., Wang, Y., Chen, N., . . Zhao, J. (2014). Effects of smoking, depression, and anxiety on mortality in COPD patients: a prospective study. Respiratory care, 59(1), 54-61. doi:10.4187/respcare.02487

Matte, D., Pizzichini, M., Hoepers, A., Diaz, A., Karloh, M., Dias, M., \& Pizzichini, E. (2016). Prevalence of depression in COPD: A systematic review and meta-analysis of controlled studies. Respiratory Medicine, 117, 154-161. doi:10.1016/j.rmed.2016.06.006

Mental Health Foundation. (2019). Smoking and Mental Health Retrieved from https://www.mentalhealth.org.uk/a-to-z/s/smoking-and-mental-health

Michal, M., Wiltink, J., Reiner, I., Kirschner, Y., Wild, P. S., Schulz, A., . . Beutel, M. E. (2013). Association of mental distress with smoking status in the community: Results from the Gutenberg Health Study. Journal of Affective Disorders, 146(3), 355-360. doi:10.1016/j.jad.2012.09.019

National Institute of Mental Health. (2019). Major Depression. Retrieved from https://www.nimh.nih.gov/health/statistics/major-depression.shtml

Newman, M., Sime, A., \& Corcoran-Perry, S. (1991). The Focus of the Discipline of Nursing Advanced Nursing Science, 14(1), 1-6.

Organization, W. H. (2019). Tobacco. Retrieved from https://www.who.int/news-room/factsheets/detail/tobacco

Patient-Centered Primary Care Collaborative. (2019). Instructional Manual: Instructions for Patient Health Questionnaire (PHQ) and GAD-7 Measures. Retrieved from https://www.pcpcc.org/sites/default/files/resources/instructions.pdf

Polifroni, C. E., \& Welch, M. (1999). Nursing and philosophy of science: Connections and disconnection. In C.E. Polifroni \& M. Welch (Eds.), Perspectives on philosophy of science in nursing: An historical and contemporary anthology Philadelphia, PA: Lippincott

Polit, D. F., \& Beck, C. T. (2017). Nursing research: Generating and assessng evidence for nursing practice (10 ed.). Philadelphia: J.B. Lippincott Company 
Prochaska, Das, \& Young-Wolff. (2017). Smoking, Mental Illness, and Public Health. Annu Rev Public Health, 38, 165-185. doi:10.1146/annurev-publhealth-031816-044618

Prochaska, \& DiClemente. (1982). Transtheoretical therapy: Toward a more integrative model of change. Psychotherapy: Theory, Research \& Practice, 19(3), 276-288. doi:10.1037/h0088437

Prochaska, \& DiClemente. (1983). Stages and processes of self-change of smoking: Toward an integrative model of change. Journal of Consulting and Clinical Psychology, 51(3), 390395. doi:10.1037//0022-006X.51.3.390

Prochaska, \& Velicer. (1997). The Transtheoretical Model of Health Behavior Change American Journal of Health Promotion 12(1), 38-48.

Prochaska, Velicer, DiClemente, \& Fava. (1988). Measuring processes of change: Applications to the cessation of smoking. Journal of Consulting and Clinical Psychology, 56(4), 520528. doi:10.1037//0022-006X.56.4.520

Richardson, S., McNeill, A., \& Brose, L. S. (2019). Smoking and quitting behaviours by mental health conditions in Great Britain (1993-2014). Addictive behaviors., 90, 14-19.

Shi, Y. (2014). Smoking cessation among people seeking mental health treatment. Psychiatric services (Washington, D.C.), 65(7), 957-960. doi:10.1176/appi.ps.201300444

Smoke Free. (2019a). Health Effects. Retrieved from https://smokefree.gov/quit-smoking/whyyou-should-quit/health-effects

Smoke Free. (2019b). Managing Withdrawal Retrieved from https://smokefree.gov/challengeswhen-quitting/withdrawal/managing-withdrawal

Steinberg, M. L., Williams, J. M., \& Li, Y. (2015). Poor mental health and reduced decline in smoking prevalence. American journal of preventive medicine, 49(3), 362-369. doi:10.1016/j.amepre.2015.01.016

Taylor, G., McNeill, A., \& Aveyard, P. (2015). Does deterioration in mental health after smoking cessation predict relapse to smoking? BMC Public Health, 15, 1150. doi:10.1186/s12889-015-2473-Z

Toljamo, T., Kaukonen, M., Nieminen, P., \& Kinnula, V. L. (2010). Early detection of COPD combined with individualized counselling for smoking cessation: A two-year prospective study. Scandinavian Journal of Primary Health Care, 28(1), 41-46. doi:10.3109/02813431003630105

United Health Foundation. (2019). Smoking in West Virginia. Retrieved from https://www.americashealthrankings.org/explore/annual/measure/Smoking/state/WV

United Health Foundation. (2021). Retrieved from https://www.americashealthrankings.org/explore/annual/measure/Depression_a/state/WV

United States Census Bureau. (2019). Quick Facts West Virginia Retrieved from https://www.census.gov/quickfacts/fact/table/WV/INC910219\#INC910219

Velicer, W. F., DiClemente, C. C., Prochaska, J. O., \& Brandenburg, N. (1985). Decisional balance measure for assessing and predicting smoking status. Journal of Personality and Social Psychology, 48(5), 1279-1289. doi:10.1037//0022-3514.48.5.1279

West Virginia Department of Health and Human Resources. (2021). Statistics about the Population of West Virginia Retrieved from https://dhhr.wv.gov/hpcd/data_reports/Pages/Fast-Facts.aspx

Woody, D., DeCristofaro, C., \& Carlton, B. G. (2008). Smoking cessation readiness: Are your patients ready to quit? Journal of the American Academy of Nurse Practitioners, 20(8), 407-414. doi:10.1111/j.1745-7599.2008.00344.x 
World Health Organization. (2019). Tobacco. Retrieved from https://www.who.int/newsroom/fact-sheets/detail/tobacco

Yohannes, A. M., Hann, M., \& Sibbald, B. (2011). The management of depressive symptoms in patients with COPD: A postal survey of general practitioners. Primary Health Care Research and Development, 12(3), 237-244. doi:10.1017/S1463423611000041 